Alma Mater Studiorum - Università di Bologna DEPARTMENT OF ECONOMICS

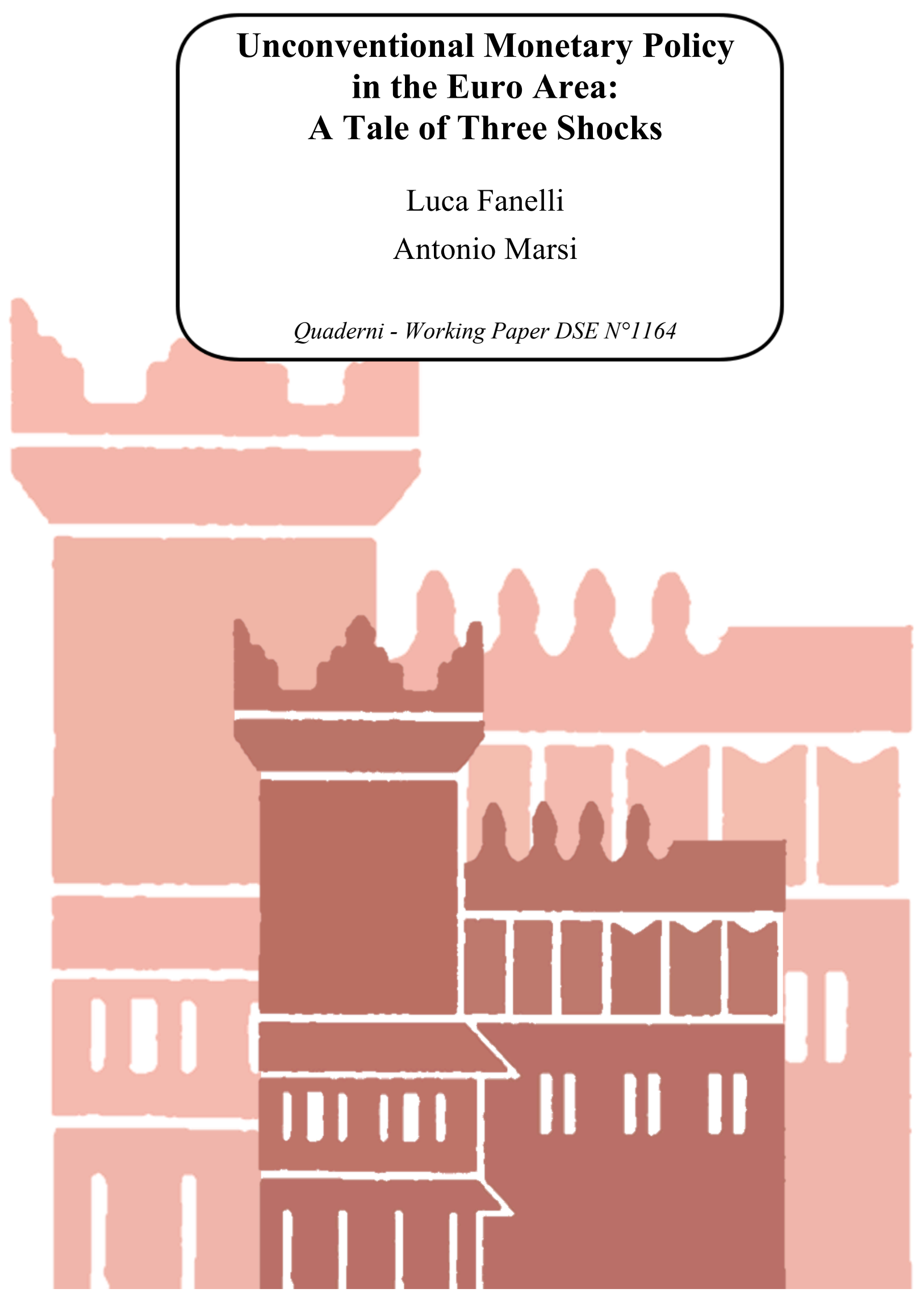




\title{
Unconventional Monetary Policy in the Euro Area: A Tale of Three Shocks
}

\author{
Luca Fanelli ${ }^{1}$ and Antonio Marsi ${ }^{* 2}$ \\ ${ }^{1,2}$ Department of Economics, University of Bologna
}

September 15, 2021

\begin{abstract}
High-frequency (HF) surprises of relevant asset prices around central bank meetings are extensively employed in the literature to identify the effects of conventional/unconventional monetary policy. This identification strategy assumes that these surprises reflect either a single unconventional 'monetary shock' or, as recently suggested, jointly an unconventional monetary shock and a central bank 'information shock'. In this paper we show that monetary policy in the euro area after 2008 is best characterized by three shocks, not two. Besides the unconventional monetary shock and the information shock, we consider a third shock resulting from the ECB directly managing fragmentation risk in the sovereign bond market. We call this additional shock 'spread shock', and show that it permits to solve a puzzle we observe in HF comovement of long term risk free rates and sovereign spreads around press conferences. We identify the dynamic causal effects produced by the three shocks through a proxy-SVAR methodology which, using HF surprises of the euro area risk-free yield curve, stock prices and sovereign spreads, combines sign-restrictions with narrative restrictions and then extracts external variables (instruments) from an admissible identification set. Empirical results, obtained through a daily proxy-SVAR and Local Projections based on monthly data, reveal that the spread shock represents an important ingredient of the transmission mechanism of the monetary policy after the Global Financial Crisis. It reflects ECB's attempt to offset self-fulling expectations of default in the euro area sovereign debt markets and behaves as a complement, not a substitute of the information shock.
\end{abstract}

Keywords: European Central Bank, Monetary Policy Shock, Proxy-SVAR, Spread Shock JEL codes: E43, E44, E52,E58,G10

\footnotetext{
*Corresponding author. Email: antonio.marsi2@unibo.it
} 


\section{Non - Technical Summary}

After the Great Recession, all major central banks have implemented extraordinary unconventional measures to fulfill their mandates. Understanding the effects that these policies produce in the economy is fundamental. In the euro area the job of the European Central Bank has been complicated by the sovereign debt crisis and the subsequent fragmentation in the sovereign debt market. In this paper we posit that the ECB has a fundamental role in managing the expectations about a breakup of the euro area and/or a default/redenomination of peripheral sovereign debt and uses this ability to manage fragmentation risk, which shows up in sovereign spreads.

In this paper, we implement a novel methodology that allows us to identify this particular aspect of ECB's policy in high-frequency (HF) variations in asset prices around press conferences of the ECB. HF variations are a powerful tool to identify unconventional monetary policy shocks, as they measure unexpected changes in monetary policy instruments. This identification strategy assumes that these surprises reflect either a single unconventional 'monetary shock' or, as recently suggested, jointly an unconventional monetary shock and a central bank 'information shock'. The latter has to do with the idea that during press conferences central banks, besides announcing monetary policy measures, also reveal to the public their view about the future state of the economy, thus influencing expectations of markets' participants.

We add to this two-shocks description a third shock, labeled spread shock, which reflects ECB's attempt to offset self-fulling expectations of defaults in the euro area sovereign debt markets and behaves as a complement, not a substitute of the information shock. We identify the dynamic causal effects produced by the three shocks through a proxy-SVAR methodology which, using HF surprises of the euro area risk-free yield curve, stock prices and sovereign spreads, combines signrestrictions with narrative restrictions and then extracts external variables (instruments) from an admissible identification set. Empirical results, obtained through a daily proxy-SVAR and Local Projections based on monthly data, reveal that the spread shock represents an important ingredient of the transmission mechanism of the monetary policy after the Global Financial Crisis. 


\section{Introduction}

Since Kuttner (2001) to most recent studies, high-frequency (HF) variations in asset prices around relevant monetary policy events have been largely employed in the monetary literature to identify the effects of policy surprises on interest rates and macroeconomic variables; see among others, Gürkaynak et al. (2005), Cochrane and Piazzesi (2002), Hamilton (2008), Campbell et al. (2012), Gertler and Karadi (2015) and Altavilla et al. (2019). The success of this approach has to be found in its ability to solve the endogeneity issue related to the analysis of monetary policy which had been previously tackled by resorting to recursive ordering in Structural Vector Autoregressions (SVAR) (Christiano et al. 1999). The assumption at the basis of HF identification methods is that surprises in the narrow window around monetary policy announcements solely reflect unanticipated monetary shocks.

Recent studies have shown that HF variations of asset prices give rise to unexpected puzzling comovements which suggest that other forces, different from pure monetary policy shocks, might influence these variations; see Nakamura and Steinsson (2018), Cieslak and Schrimpf (2019), Jarocinski and Karadi (2020), Andrade and Ferroni (2021), Hoesch et al. (2019) and Miranda-Agrippino and Ricco (2021). For instance, Jarocinski and Karadi 2020) show that for almost $40 \%$ of monetary events in the euro area a positive comovement between the 3-month interest rate and the stock market index is observed. According to conventional wisdom, a monetary shock should generate a negative comovement, in the sense that e.g. a contractionary shock should increase interest rates and decreases stock prices (Bernanke and Kuttner, 2005). This literature has put forward the idea that a 'central bank information effect', beyond a monetary policy shock, is reflected in HF variations and transmitted to the economy. Central banks have high-quality information about the future state of the economy which is disclosed during announcements affecting market expectations. This may generate puzzling comovements between yields and stock prices because e.g. a release of positive information may simultaneously drive up expectations about future economic growth, stock prices and interest rates. The issue becomes particularly relevant when one wants to identify unconventional monetary policy shocks which typically affect the yield curve at mediumto-long maturities. Long term rates incorporate expectations of market's participants, hence they crucially reflect the information effect.

In this paper we devote attention to the euro area and HF variations of asset prices surprises around press conferences of the ECB. As is known, monetary policy in the euro area is complicated by the fact that there are 19 sovereign bond markets which make fragmentation risk a concern. To account for fragmentation risk, we include sovereign spreads of peripheral countries among the analyzed HF variations and focus on the windows during which unconventional policies are announced and discussed. Doing so, we observe puzzling correlations between HF variations of risk premia on Italian and Spanish bonds and risk-free rates at different maturities that hardly can be reconciled with the 'two-shocks' (monetary/information) paradigm. Indeed, while one would 
expect a positive correlation between these HF variations, the data reveal periods of negative correlations that tend to cluster around debt crisis episodes. An unconventional monetary shock such as the one resulting from forward guidance or quantitative easing (QE) policies should reduce (increase) medium/long term rates and reduce (increase) risk premia on risky sovereign bonds; see e.g. the model in Altavilla et al. (2015) where QE shocks affect credit risk of peripheral bonds. Likewise, an information shock does not suffice alone to explain why the observed puzzling correlations cluster around debt-crisis periods. It is therefore tempting to rationalize the observed puzzle by considering explicitly the ECB management of expectations on sovereign debt crises, see e.g. Lane (2021). Since the famous 'whatever it takes' speech by Mario Draghi on July 26, 2012, market participants have metabolized that the ECB plays an active role in keeping expectations about a breakup of the euro area and a re-denomination of peripheral debt into local currencies under control (De Grauwe, 2011).1

We show that the ECB's attempt to eliminate self-fulfilling expectations of default in the euro area sovereign debt markets motivates the case for the identification of a 'third shock', conventionally labeled spread shock, that complements the monetary policy shock and the information shock. The spread shock has peculiar features and arises from the ECB announcements directly affecting, in particular periods and/or in correspondence of particular episodes, expectations about a break-up of the euro area measured by credit/redenomination risk premia. The identification of this shock allows us to fully rationalize the joint behavior observed in the HF surprises of riskfree rates, stock prices and sovereign spreads during the entire lifetime of the euro area. From a theoretical point of view, the spread shock can be motivated by considering a stylized model of multiple equilibria where, along the lines of De Grauwe and Ji (2013), a central bank affects agents' expectations in a monetary union to reduce fragmentation risk. The central bank manages yield spreads actively by shifting expectations about the probability of default of a given country from an equilibrium in which default can be beneficial to the country to an equilibrium in which the cost of defaulting overcomes the benefit.

Albeit the information shock and the spread shock may imply similar comovement of asset prices, they are different in nature. To isolate one from each other, we rely on the fact that the realizations of the spread shock are clustered around debt crisis periods, which is not the case for the information shock. Furthermore, by its very nature, the impact of the spread shock on sovereign spreads should be stronger than the impact of the information shock. This crucial difference makes it possible to conduct our identification exercise. By combining different types of restrictions and relying on a two-step methodology, we point-identify the three structural shocks simultaneously

\footnotetext{
${ }^{1}$ More recently, in the aftermath of the Covid-19 pandemic outbreak, in the press conference on March $12^{t h}$ the new Governor Christine Lagarde stated: 'we don't close spreads', referring to the responsibility of the ECB to compress sovereign risk premia. The huge reaction of financial markets to this statement has shown the expectations were quite the opposite: markets participants were expecting the ECB to effectively close spreads. This event further revealed the active role of the ECB in controlling sovereign spreads.
} 
and show that they produce appreciably distinct dynamic causal effects on the euro area economy. We show that the spread shock provides an explanation of the wrong-signed comovement observed between stock prices and interest rates complementary to that provided by Jarocinski and Karadi (2020).

On the methodological and empirical sides, we trace out the dynamic causal effects produced by the three shocks by a two-steps approach. In the first-step, we use the euro area monetary policy event-study database (EA-MPD) built by Altavilla et al. (2019) to approximate HF surprises in interest rates, spreads and the stock market by three factors. By combining sign restrictions with other type of restrictions, the three factors are interpreted as an unconventional monetary policy factor, an information factor and a spread factor, respectively ${ }^{2}$ In the second-step, we use three 'representative' factors extracted from the set identified in the previous step as external variables in a proxy-SVAR estimated on data at daily frequency. Doing so, we simultaneously point-identify the dynamic causal effects produced by the (unconventional) monetary policy shock, the information shock and the spread shock on target financial variables such as the stock market index, the 2-year euro area inflation-linked swap rate and the EUR-USD nominal exchange rate. Furthermore, we quantify the impact of the three shocks on euro area industrial production using the three representative factors as external instruments in Local Projections (LP-IVs) a là Stock and Watson (2018) estimated on monthly data.

Empirical results on the period from January 2002 to June $2024^{3}$ can be summarized as follows. The estimated daily proxy-SVAR shows that the introduction of the spread shock improves the identification of the unconventional monetary shocks. The latter in the 'three-shocks paradigm' generates a positive comovement between the risk-free yield curve and sovereign spreads along the lines of Altavilla et al. (2015). A reduction in sovereign spreads due to an expansionary spread shock policy, increases the risk-free yield curve for approximately 6-months, as predicted by our stylized multiple equilibria model. Furthermore, the introduction of the spread shock does not have drastic implications on the estimated effects of the information shock, suggesting that our analysis complements the central bank information effect. At the monthly-frequency, we find that the spread shock exerts significant effects on euro area macroeconomic variables and produces a slightly more effective response in inflation relative to the unconventional monetary policy shock.

The suggested 'three-shocks' (monetary/information/spread) paradigm provides a convenient characterization of the PEPP (Pandemic Emergency Purchase Program) launched by ECB in 2020 to face the crisis caused by the COVID-19 pandemic outbreak. The PEPP is a QE program which entails a major difference with respect to the previous QE launched by the ECB in 2015 (the APP).

\footnotetext{
${ }^{2}$ We refer to e.g. Swanson (2017), Antolín-Díaz and Rubio-Ramírez (2018), Furlanetto et al. (2019), Ludvigson et al. (2020) and Caggiano et al. (2021) for the role of narrative/institutional restrictions in structural shocks identification.

${ }^{3}$ In the daily proxy-SVAR the sample starts from August 2005, due to lack of data availability for the earlier period.
} 
The goal of the APP was to intentionally affect the common component of long term sovereign rates, and for this reason purchases of sovereign bonds were split across euro area countries according to a fixed rule based on the economic size of each country: the rationale was not to favor certain countries over others. Instead, the PEPP is designed in a more flexible way and devotes more attention to countries under stress. As explained by Lane (2021), the PEPP entails a dual objective: keeping the risk-free yield curve low and managing fragmentation risk. Looked with the lens of our three-shocks decomposition, HF variations associated with PEPP-related announcements embody both unconventional and spread shocks, hence our methodology permits to evaluate the efficacy of such a dual-objective policy.

Organization. The rest of the paper is organized as follows. Section 2 explains how our contribution relates to the literature on HF identification of monetary policy shocks. Section 3 introduces the puzzle one faces when focusing on HF responses of periphery spreads to ECB announcements. Section 4 rationalizes the novel spread shock and focuses on some of its implications. Sections 5 and 6 describe the methodology and present the empirical results obtained from a proxy-SVAR estimated on data at daily frequency to capture the impact of the three shocks on financial variables. Section 7 investigates the macroeconomic effects produced by the three monetary policy shocks considering LP-IVs estimated on data at monthly frequency. Section 8 contains some concluding remarks.

The stylized theoretical used to rationalize the role of the spread shock is discussed in Appendix A.1 Appendix A.2 provides further empirical evidence on the spread shock. Appendix B summarizes the methodology used for the estimation of a proxy-SVAR based on two shocks (monetary/information) only. Appendix C tests the robustness of our main empirical results by replacing Italian sovereign spreads with Spanish ones.

\section{Connections with the literature}

The use of high-frequency data to identify monetary policy shocks dates back to Kuttner (2001) and Cochrane and Piazzesi (2002). The seminal work of Gürkaynak et al. (2005) first suggested to use factor (principal component) analysis to extract time-series interpretable as monetary policy factors from a bunch of yields variations. Recently, a fast developing literature to which this paper speaks focuses on identifying multiple shocks around monetary policy events. Nakamura and Steinsson (2018) and Miranda-Agrippino and Ricco (2021) focus on US data, while Jarocinski and Karadi (2020) and Andrade and Ferroni (2021) analyze the euro area as well. Jarocinski and Karadi (2020) and Andrade and Ferroni (2021) use sign restrictions to disentangle information shocks from monetary policy shocks by looking at HF responses of the stock market and inflation expectations, respectively. In the first-step of our empirical identification exercise we partially build on these methods used by the aforementioned authors. 
Our paper is also related to Leombroni et al. (2021) who, adopting a core/periphery perspective, focus on the effects of ECB communication of the sovereign yields of the euro area. They identify two shocks from HF surprises observed around press conferences: an interest rate shock and a risk premium shock. The first shock captures surprises due to forward guidance and information effects from ECB communication and announcements about the future path of the short term rate. This shock is identified by principal component analysis, considering variations in the OIS rates along the yield curve. The risk premium shock is meant to capture ECB policies affecting directly the risk premium and credit risk of peripheral countries. This second shock is identified by taking the variations in the stock market index which are orthogonal to the first shock. We differ from Leombroni et al. (2021) in two important dimensions. First, the interest rate shock in Leombroni et al. (2021) conveys both the information and monetary effect as they do not exploit the comovements of OIS rates and stock prices to distinctly separate the two components. Second, we identify our spread shock (the analog of their risk premium shock) using a different empirical identification strategy which requires taking a stand on the expected comovement between OIS rates and sovereign spreads.

Cieslak and Schrimpf (2019) have a direct contact with our analysis in the sense that they also assume three types of structural shocks affecting HF variations of interest rates around monetary policy announcements: a monetary shock, an information shock and a risk premium shock, where the latter is tied to news affecting the price of risk in financial markets. To identify these three shocks these authors exploit sign restrictions on HF comovement of the yield curve and stock prices. Similarly to Cieslak and Schrimpf (2019), we also identify a risk shock - our spread shock - yet with an important difference. While Cieslak and Schrimpf (2019) interpret this third shock as the realization of 'flight-to-safety' episodes which move the yield of safe government bonds downwards, we focus more specifically on the risk premium on the sovereign bonds of euro area peripheral countries, and exploit the idea that the third structural shock affects the euro area risk-free yield curve through expectations.

A recent large literature has focused on estimating the effects of unconventional monetary policies in the euro area. Prominent examples (that do not exhaust the list) are e.g. Altavilla et al. (2015), Altavilla et al. (2016), Gambetti and Musso (2017), Krishnamurthy et al. (2018) and Dewachter et al. (2016). These studies focus on specific types of unconventional measures separately, while our aim is to provide a comprehensive estimate of monetary policy shocks over the whole lifetime of the euro area. Inspired by the studies made for the US by e.g. Gürkaynak et al. (2005) and Swanson (2017), Altavilla et al. (2019) move towards this direction building factors extracted from HF variations of the risk-free yield curve around ECB meetings. We use this important dataset for the construction of the factors used to simultaneously identify the three structural shocks. In a comment of the work by Altavilla et al. (2019), Wright (2019) remarks the need to focus also on HF variations in sovereign spreads in order to fully characterize ECB policies 
and construct a 'save-the-Euro-factor' which resembles very much our spread shock. While we are fully sympathetic to Wrigth's (2019) suggestion, we depart from his analysis along two dimensions. First, we do not dismiss the importance of the information shock which is identified jointly with the monetary shock and the spread shock. Second, we show that the 'save-the-Euro-factor' is indeed embedded in the HF variations of the risk-free yield curve and can not be ignored; see e.g. Altavilla et al. (2019). In other words, by looking at HF movements in the risk-free yield curve to estimate pure monetary shocks, one inevitably faces the issue that some of these variations are due to sovereign spread targeting policies, thus estimates can result biased.

Our paper is also related to Hachula et al. (2019), who solve the issue of disentangling different types of monetary policy shocks in the euro area through an identification strategy that splits the estimation sample into two parts: a 'phase 1' period (2007-2014) for which they assume the ECB targets periphery spreads, and a 'phase 2' period (2014-2016) for which they maintain the ECB targets the risk-free yield curve. Our approach allows to account for this multiplicity of structural shocks embedded in HF variations of asset prices without the need to split a-priori the estimation sample.

Finally, on the methodological side we contribute to the fast growing literature that exploits information from external variables to identify dynamic causal effects in proxy-SVARs (SVARsIV) in the special case in which multiple instruments are used for multiple target shocks; see e.g. Mertens and Ravn (2013), Mertens and Montiel Olea (2018), Lakdawala (2019) and Angelini and Fanelli (2019). To our knowledge, ours is the first contribution in the proxy-SVAR/monetary policy context where three structural shocks are point-identified simultaneously. As is known, proxies alone do not suffice to identify multiple target shocks and additional restrictions must complement the specification of the model. One of the main challenges of our empirical identification exercise is to accommodate these additional restrictions. The methodological section of the paper discusses in detail how we face this issue.

\section{The OIS-spread puzzle and policy surprises: some pre- liminary evidence}

In this section we devote our attention to the empirical puzzle that motivates a novel spread shock peculiar to the euro area which complements the monetary policy shock and an the information shock. The puzzle arises from the observed behavior of HF variations in asset prices around press conferences regularly held by the ECB. As explained in details in e.g. Altavilla et al. (2019), monetary policy decisions in the euro area are announced in two separate steps. First, decisions related to policy rates are announced in the press release. Later, a press conference is held by the ECB governor. In this occasion, unconventional policies are announced, policy measures are discussed and the view of the ECB about future developments in euro area economy is put forth. 
This two-steps announcing procedure can be exploited to disentangle HF surprises of asset prices into different components related to different aspects of the policies pursued by the ECB.

Figure 1 taken from Altavilla et al. (2019), shows some examples of how 2-year OIS rates move during the days in which the ECB Governing Council meets. The solid and dashed vertical red lines correspond to the time at which the press release is made public and the beginning of the press conference, respectively. The graph shows that jumps during the day cluster around these two major events 4

Throughout the paper we use the EA-MPD dataset constructed by Altavilla et al. $(2019)^{5}$ and focus on HF variations observed around press conferences only. We disregard changes around the press release as our interest lies on unconventional monetary policy only and doing so we clean out HF variations from the movements reflecting short term policy-rate decisions.
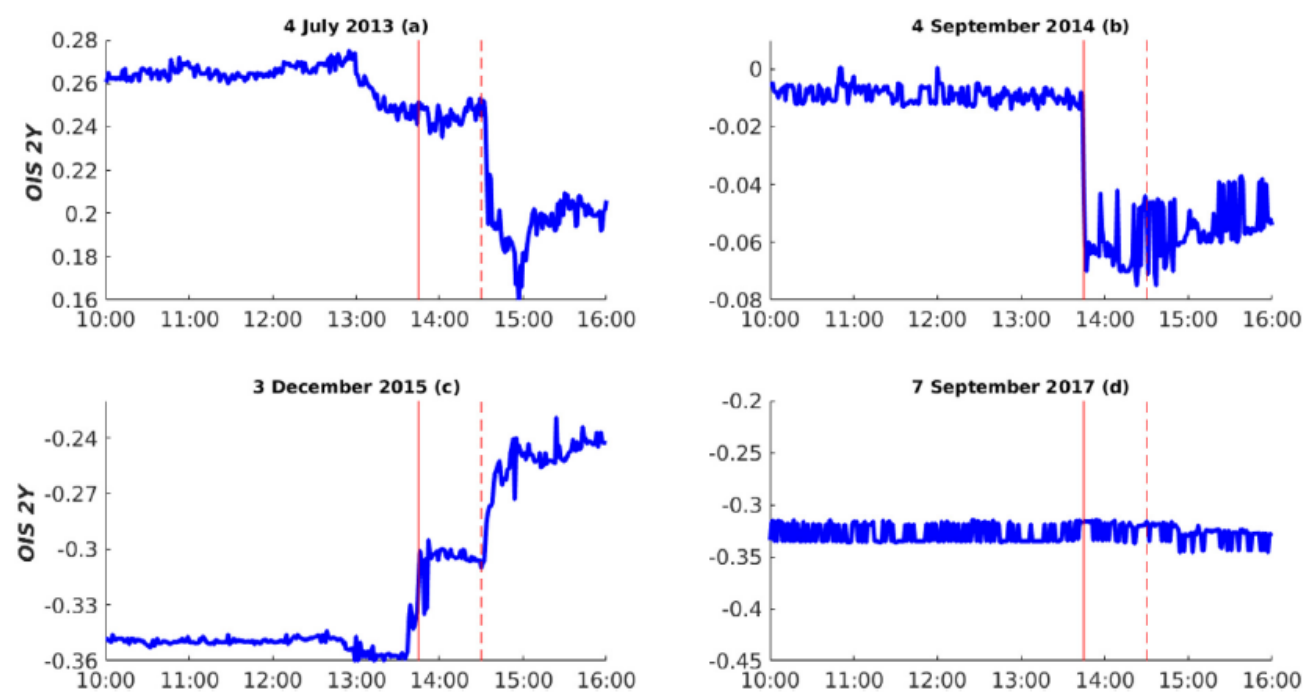

Figure 1: Examples of intra-day variations of the 2-year OIS around press release and press conference. Graphs are taken from Altavilla et al. (2019).

Moreover, to better characterize unconventional policy, we observe HF surprises in the whole term structure of OIS rates. Several contributions discuss how conventional and unconventional monetary shocks affect risk-free rates along the term structure; see Gürkaynak et al. (2005), Hanson and Stein (2015) and Altavilla et al. (2019), among others. Typically, conventional shocks are most effective in the short horizon; forward guidance affects the yield curve at medium horizons; QE is

\footnotetext{
${ }^{4}$ OIS (Overnight Indexed Swaps) are derivatives in which a fixed leg of a given time-length (from 3 months to 10 years) is exchanged for a floating leg given by the EONIA rate. These contracts are used by investors for two objectives: bet on the future path of the short term rate and insure against duration risk. For this reason long term OIS rates are equivalent to the yield of a default-free long term bond, net of any difference coming from "convenience yields" on sovereign bonds. These features made them particularly suitable to be used as reference risk-free yields for the Euro Area.

${ }^{5}$ More precisely, Altavilla et al. (2019) construct the asset price change around the press conference by taking the median price in the 14:15-14:25 interval as the pre-conference quote and the median price in the 15:40-15:50 interval as the post-conference quote. Press conference starts at 14:30.
} 
most effective at long horizons. A monetary shock, being it conventional or unconventional, should generate a negative comovement of risk-free yields and the stock market Bernanke and Kuttner, 2005). Indeed, an unexpected increase in interest rates depresses future economic activity and then causes a downward revision of stock prices. However, as explained by Jarocinski and Karadi (2020), more than $40 \%$ of the HF changes of the 3-months OIS rates and the STOXX50 index around ECB announcement days display a wrong-sign comovement, i.e. positive rather than negative. Jarocinski and Karadi (2020) focus on HF variations around both the press release and the press conference for each relevant day and sum the two variations. They ascribe the puzzling comovements to the information effect.

Figure 2 displays how the fraction of wrong-signed events associated with ECB announcements has changed in the last 15 years. The fractions in the graph have been computed through a 2-years rolling window analysis as follows. Consider all dates in which the ECB held a press conference in the period 2002-2020. For each of these dates, $d$, let $\Delta O I S_{d, m}, m=\{1$-year, 2-years, 5 -years, 10-years $\}$ denote HF variations in the OIS rates at different maturities, and let $\triangle S T O X X 50_{d}$ be the variations in the STOXX50 index. Henceforth, we use the symbol ' $(\Delta x, \Delta z)_{+}$' to indicate that the variables $x$ and $z$ vary in the same direction and ' $(\Delta x, \Delta z)_{-}$' to indicate that $x$ and $z$ vary in opposite directions. The plots in Figure 2 correspond to the quantities

$$
f_{d, m}=\frac{\# \text { of episodes in the last two years for which }\left(\Delta O I S_{d, m}, \Delta S T O X X 50_{d}\right)_{+}}{\# \text { total episodes in the last two years }} .
$$

The graph reveals that the fraction of wrong-signed events tends to cluster at the beginning and at the end of the sample period with peaks concentrated during debt crisis periods or episodes of financial and fiscal stress for euro area countries. This preliminary evidence suggests that the prevalence of wrong-signed events could be related to the role played by the ECB in managing sovereign debt crisis during the debt crisis and not to a 'pure' information effects.

We include sovereign spreads into the picture. While a negative comovement is expected for OIS rates and the stock index, we would expect positive comovements of OIS rates and sovereign spreads around ECB press conferences if monetary shocks were the only driving force in the narrow windows considered. Notice that in this paper we refer to the unconventional monetary shock as a broad category encompassing shocks due to e.g. Forward Guidance or QE. We interpret it as the unsystematic component of a monetary policy rule where on the left-hand side we have the OIS risk-free rate at medium-long maturity. An unconventional monetary shock, which affects long term risk free rates, should generate a positive comovement between OIS rates and euro area periphery risk premia around ECB press conferences ${ }^{6}$ Think about a Forward Guidance shock arising from the ECB announcing an unexpected decline in the future path of short term interest

\footnotetext{
${ }^{6}$ We will refer to OIS rates as the risk-free rates, though this definition is not completely appropriate, as long term OIS commands a risk premium as they incorporate some duration risk. Nonetheless they are risk-free in the sense that they don't carry any default/re-denomination risk premium.
} 


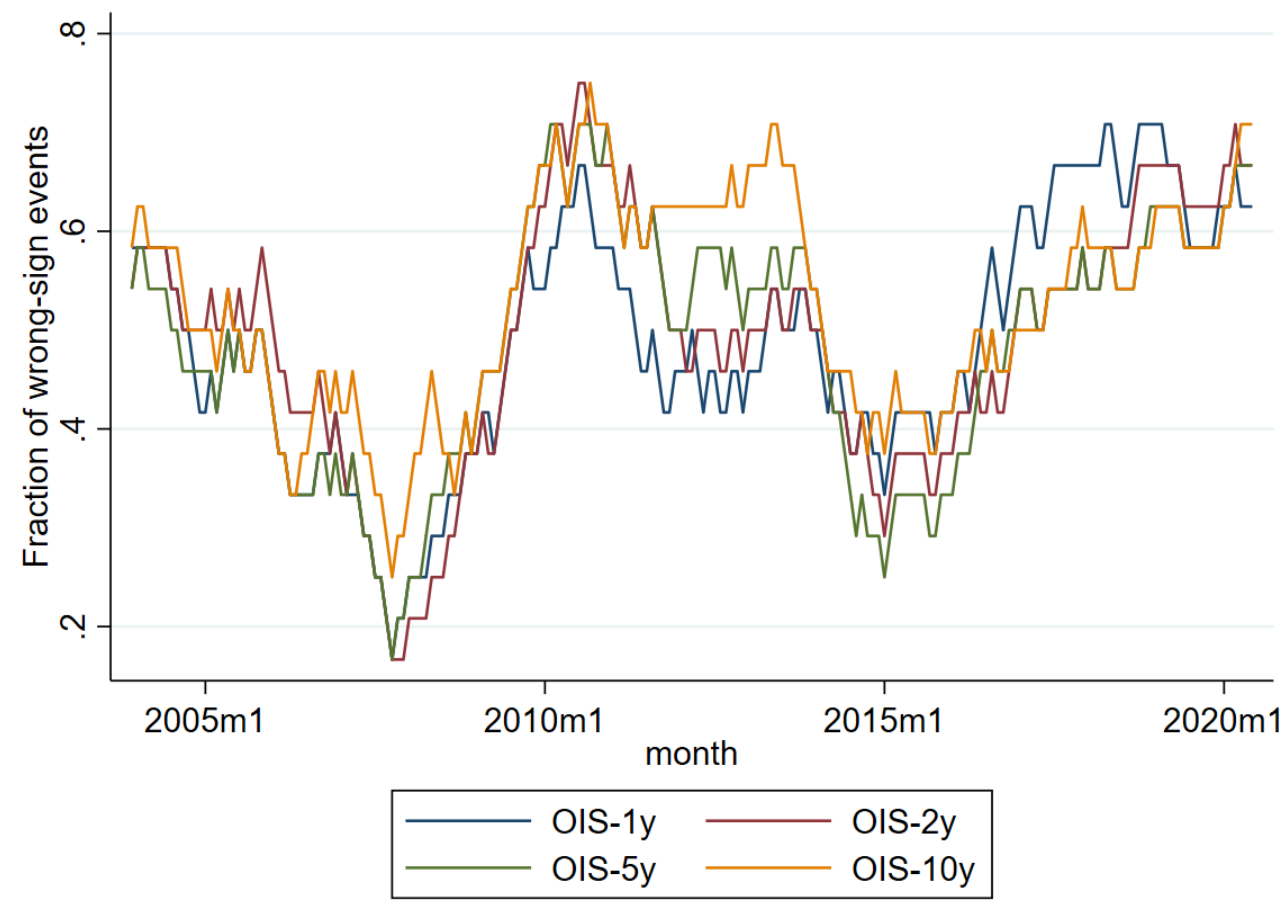

Figure 2: Fraction of press conferences displaying wrong-sign comovements, i.e. positive comovements of OIS rates and the STOXX50 index, computed on a 24-months rolling window. The x-axis reports the last month of the window.

rates. This causes a drop in medium-to-long term rates which stimulates the economy and increases stock market indices and, arguably, also reduces periphery risk premia. This final effect has to do with a increased performance of the economy in the future which therefore relieves pressures on high sovereign debts. Similarly, as shown in the model by Altavilla et al. (2015), QE reduces the price of risk for both long-term risk-free yields and risky peripheral sovereign debt through the portfolio-rebalancing channel[ [7]

Compared to the US and other major economies, the euro area experiments a fragmented sovereign debt market, in which associated to each sovereign debt there exists a different credit (or redenomination) risk. During the debt crisis started after the Great Recession of 2008, this issue has become enormously relevant. It became clear that to contain the spreads of peripheral countries the ECB had to manage the perceived risk about a break-up of the euro area. Starting from the famous 'whatever it takes' speech by Mario Draghi on $26^{\text {th }}$ July 2012, the ECB was able to restore confidence in the solidity of the monetary union and improve the convergence of sovereign rates around the euro area. This goal has been reached through an accommodating communication

\footnotetext{
${ }^{7}$ Furthermore, policies like LTROs (Long Term Refinancing Operations) are aimed at increasing the supply of long term loans by banks, thus reducing long term risk free rates. These liquidity injections have been used by commercial banks also to increase their exposure to risky sovereign debt (Crosignani et al. 2019), again leading to a reduction in sovereign spreads.
} 
strategy and unconventional measures such as the OMT, the LTRO and the QE.

Figure 3 plots regression coefficients obtained from 5-year rolling window regressions of $\mathrm{HF}$ variations of a measure of the risk premium on Italian bonds, as captured by the spread between 10-year Italian and OIS rates, around ECB press conferences on HF variations of OIS rates from 1-year to 10-year maturity. These regressions are carried out along the lifetime of the euro area. Figure 4 plots regression coefficients of analog regressions obtained considering the risk premium on Spanish bonds. A clear pattern emerges from these graphs. In the initial period until 2010, regression coefficients were zero as sovereign spreads were very low and not varying at all. During the debt crisis regression coefficients turn out to be negative and become significant when using the 10-year OIS rates as regressor. When considering the QE period 2014-2015, the estimated regression coefficients become positive and significant. The change of sign in the correlation over time suggests that the monetary shocks that generate a positive correlation between risk premia and risk free rates have been prevailing in the QE period, while other mechanisms have been predominant during the debt crises with the effect of counterbalancing the positive comovement implied by monetary shocks. The information shock does not suffice alone to explain such a marked change occurred over the lifetime of the euro area. We argue that the marked change can be ascribed to the ECB influencing expectations about the break-up of the euro area, redenomination of peripheral debt and sovereign defaults.

\section{ITALY}
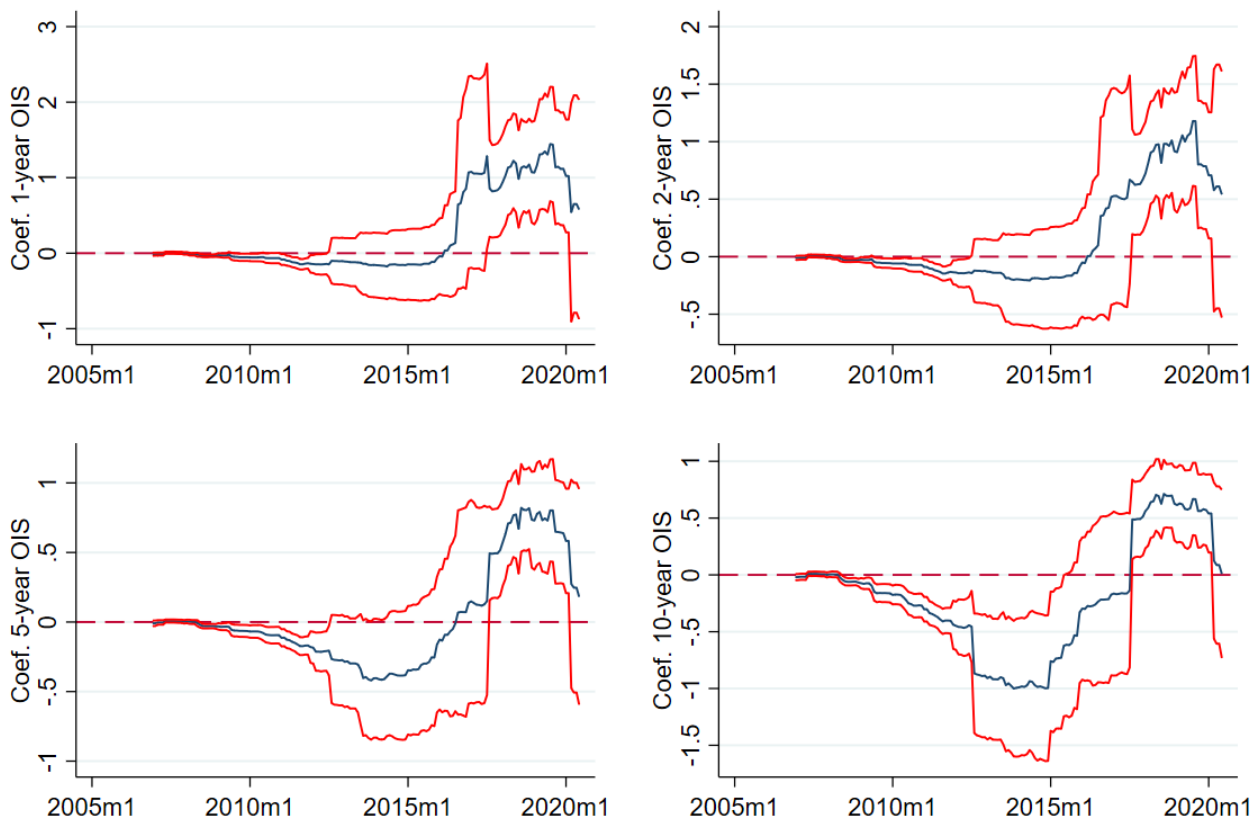

Figure 3: Blue lines plot coefficients estimated from 60-months rolling window regressions of the 10-year IT-OIS spread on OIS rates around ECB press conferences. Red lines represent $95 \%$ confidence intervals. The x-axis reports the last month of the window. 

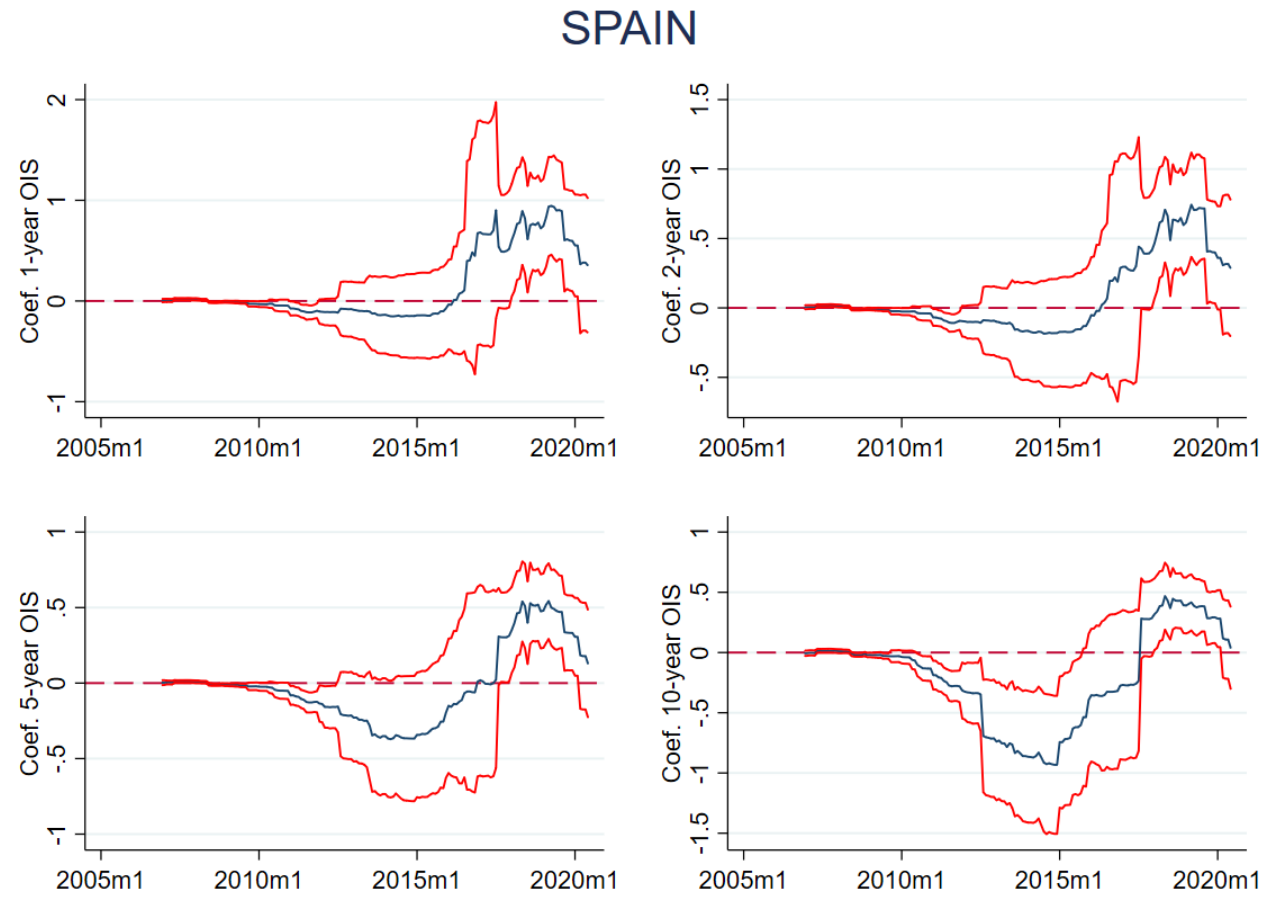

Figure 4: Blue lines plot coefficients estimated from from 60-months rolling window regressions of the 10-year ES-OIS spread on OIS rates around ECB press conferences. Red lines represent $95 \%$ confidence intervals. The $\mathrm{x}$-axis reports the last month of the window.

\section{Managing fragmentation risk: the spread shock}

In this section we frame the role of the spread shock within a stylized theoretical model. We put forward the idea that the evidence emerging from HF surprises in the euro area documented in the previous section can be explained by emphasizing the role of an unaccounted (so far) confounding factor. One way to reconcile empirical facts with theoretical arguments is to account for central bank's management of fragmentation risk in the euro area sovereign debt market. Our argument is that the ECB may influence the expectations of market's participants of a breakup of the euro area and/or the defaults of peripheral countries, and this is reflected in a spread shock embedded in HF surprises of asset prices along with other shocks. We show that the spread shock is as important as the monetary policy and information shocks in the euro area.

We formalize a stylized theoretical model which may account for the role of the spread shock in Appendix A.1 The model features an IS-LM equilibrium with fixed prices but its main implications can be easily extended to a staggering prices setup. The basic intuition is taken from De Grauwe and Ji (2013): the central bank in a monetary union may shift expectations about a default/redenomination of sovereign debt, originating multiple equilibria. More precisely, the central bank can move the economy from a 'bad' equilibrium characterized by high expectations of default and an high risk premium, to the 'good' equilibrium characterized by low expectations of 
default and low risk premium 8 The relevant interest rate that determines the equilibrium in the real economy is made up of two components: a risk-free component plus a risk premium component, hence the decrease in the risk premium component causes an improvement in real economic activity; see e.g. Altavilla et al. (2017) for the transmission of sovereign spreads to bank lending and funding conditions. Furthermore, the shift from the bad to the good equilibrium moves the risk-free components of interest rates (as measured by OIS rates in the euro area) upward, because of the central bank response to the improved economic conditions as implied by its policy rule 9 Overall, the change in expectations about default(s) determines a decline in risk premia which is accompanied by increases in risk-free rates.

Focusing on the specific case of the euro area, the shift in expectations about default of peripheral countries can be achieved by the ECB in several ways. For instance, in Darracq Pariès et al. (2020) there exists a second monetary policy rule in which the ECB adjusts its purchases of risky debt to respond to changes in risk-premia, with the ultimate goal of stabilizing the economy by supporting financial conditions (Lane, 2021). A second monetary policy rule is also featured in Sims et al. (2020), though its purpose in this contribution is to manage, by means of asset purchases, credit risk originating from capital constraints on financial intermediaries. Nonetheless, the nature of the policy rule in Sims et al. $(2020)$ is to some extent similar to the mechanism we have in mind for the management of sovereign spreads.

Our approach relies on the idea that the spread shock generates a peculiar negative comovement between sovereign spreads and risk-free rates which can be suitably exploited for identification. This central hypothesis is further corroborated by some empirical facts emerging from press conferences where the ECB had to face explicitly issues related to fragmentation risk in the sovereign debt market; see Appendix A.2 for a detailed discussion. It is worth noticing that by not taking into account the spread shock we might possibly incur into an omitted variable $(\mathrm{s}) / \operatorname{shock}(\mathrm{s})$ bias which creates two types of problems. First, if one is interested in the estimation of the effects of unconventional monetary policy on peripheral risk premia, the omission of the reverse effect that the spread shock exerts on the risk free rate may lead to underestimate the true effects. Second, even if we abstract from the periphery risk premia, using OIS rates surprises as measures of monetary policy shocks or the factors constructed by Altavilla et al. (2019) from the OIS yield curve, could lead to systematic bias the impact of the spread shock. For instance, we might interpret an increase in the long term OIS rate as a restrictive monetary policy shock that might actually arise from an 'expansionary' spread shock, that is a reduction in the risk premium. This phenomenon

\footnotetext{
${ }^{8}$ In both cases expectations are computed with respect to the actual probability of default, hence the equilibrium is characterized by rational agents. Clearly, the central bank could also move the economy in the other way around, from the bad to the good equilibrium if it stops favoring low expectations of sovereign default.

${ }^{9}$ Similarly, Darracq Pariès et al. (2016) shows, in a multi-country DSGE model, how the euro area economy responds to a shock which increases sovereign risk in peripheral countries (Italy and Spain). Euro area output and inflation decrease and the same occurs to the stock market, while risk-free rates decrease because of the central bank's commitment to a standard monetary policy rule.
} 
can in turn lead to biases in the estimates of the effect of monetary policy shocks on e.g. real economic activity and inflation. Given the short life of the euro area and the high importance played by unconventional MP in its lifetime span, this appears to be a relevant issue.

\section{Extracting multiple factors from HF surprises}

To identify multiple shocks embedded in HF surprises around ECB press conferences and evaluate their effects on financial and macro variables, we rely on a two-step procedure. In the first step, we use HF data taken from Altavilla et al. (2019) EA-MPD database to extract a set of orthogonal factors that summarize the dynamics of the euro area yield curve, sovereign spreads and the stock market. By doing so we set-identify three factors that provide a comprehensive characterization of euro area HF surprises. We then extract 'representative' factors from the identified set which are used in a second step as external instruments of a proxy-SVAR and in Local Projections, respectively. The objective in this second step is to track the responses of variables of interest to three key structural shocks. In this section we focus on the first step. The second step will be discussed in the next sections. Observe that we prefer to use the term 'factor' in place of 'shock' at this stage because, technically speaking, we consider the problem of extracting factors from euro area HF surprises which are employed in a second-step as external instruments for the (latent) structural shocks of interest.

To emphasize the importance of the spread factor, our empirical strategy starts from a specification that ignores this shock. More precisely, we consider a setup where only two factors affect movements of the OIS yield curve in the narrow windows around ECB press conferences: a monetary factor and an information factor. In this respect, the identification strategy mimics the ones pursued in e.g. Andrade and Ferroni (2021) and Jarocinski and Karadi (2020). Our objective is to show that, in addition to the reduced form evidence documented in Section 3 (see also Appendix A.2, the 'monetary-information paradigm' does not suffice to fully explain important movements in the euro area yield curve. Moving one step forward, we show that the introduction of a spread factor provides a dynamic characterization of $\mathrm{HF}$ surprises in the yield curve that would remain otherwise unexplained.

Two-factors setup. Let $\delta_{t}$ be the $5 \times 1$ vector collecting $\mathrm{HF}$ variations of OIS rates at maturities $m=1,2,5,10$, and the STOXX50 index observed around ECB press conferences in the period from January 2002 to June 2020. We assume that $\delta_{t}$ can be approximated by the model:

$$
\underset{5 \times 1}{\delta_{t}}=\underset{5 \times 2}{\Lambda} \underset{2 \times 1}{f_{t}}+\underset{5 \times 1}{e_{t}}
$$

where $f_{t}$ is a $2 \times 1$ vector of factors, $\Lambda$ is the matrix of time-invariant factor loadings associated with the two factors and $e_{t}$ is a vector of disturbances assumed to have time-invariant covariance 
matrix. The matrix counterpart of the system of equations above is given by

$$
\underset{T \times 5}{\Delta}=\underset{T \times 2}{F} \underset{2 \times 5}{\Lambda^{\prime}}+\underset{T \times 5}{e}
$$

where $T$ is the sample length. To set-identify the two factors we use a frequentist sign-restrictions approach. As is known, for any $2 \times 2$ orthonormal matrix $Q$ the system can be rotated to obtain:

$$
\Delta=(F Q)(\Lambda Q)^{\prime}+e=F^{*}\left(\Lambda^{*}\right)^{\prime}+e
$$

where $F^{*}$ and $\Lambda^{*}$ are therefore respectively the rotated factors and the rotated loadings. The vector of rotated factors is then given by $f_{t}^{*}=Q f_{t}$. We select the matrices $Q$ among the set of orthonormal matrices such that the model satisfies the following structure:

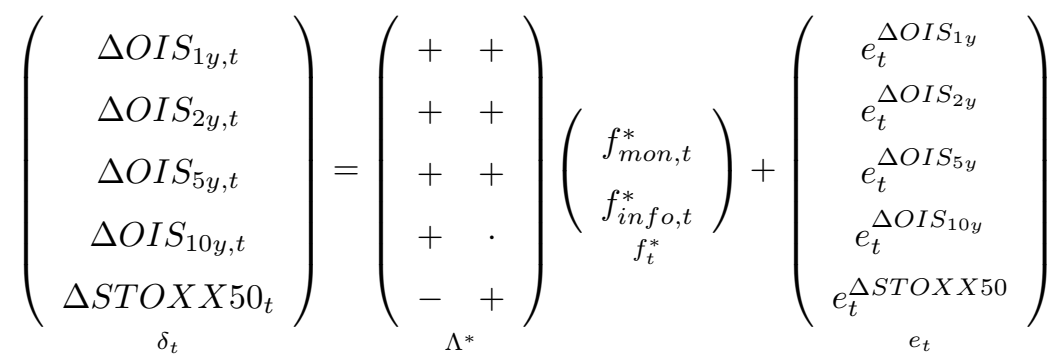

where $f_{m o n, t}^{*}$ and $f_{\text {info,t }}^{*}$ are interpreted as two (orthogonal) monetary and information factors, respectively.

In system (3), we force the monetary factor to load positively on the OIS yield curve at all maturities and negatively on the STOXX50. Instead, the information factor loads positively both on the OIS yield curve and the STOXX50. Note that, inspired by the idea that the information revealed by the ECB is unlikely to affect expectations at long horizons, we leave the coefficient that loads the information factor to the 10-year OIS rate unrestricted (see the symbol '.' in (3)). As in Jarocinski and Karadi (2020) and as it is seen from the last row of the matrix $\Lambda^{*}$, in (3) the separation of the information factor from the monetary factor in entirely based on the opposite sign response of the stock market index. The factor model in (3) is estimated by maximum likelihood. The algorithm we apply is standard; see Uhlig (2005). ${ }^{10}$ To select two 'representative factors' from the identification set, we use the MT method by Fry and Pagan (2011) 11 this delivers the (unique) vector $f_{t}^{M T}=\left(f_{m o n, t}^{M T}, f_{i n f o, t}^{M T}\right)^{\prime}, t=1, \ldots, T$.

The upper panel of Figure 5 plots the loadings estimated by regressing the quantities $\Delta O I S_{m y, t}$, $m=1,2,5,10$, on the two MT factors $f_{m o n, t}^{M T}$ and $f_{\text {info,t }}^{M T}$ with associated $95 \%$ confidence intervals.

\footnotetext{
${ }^{10}$ At each iteration, a $2 \times 2$ orthonormal matrix $Q$ is randomly generated and the matrix $\Lambda^{*}=\Lambda Q^{\prime}$ and factors $F^{*}=F Q$ computed. After proper normalization of signs across columns, the validity of the sign restrictions is checked: the generated $\Lambda^{*}$ and $F^{*}$ that do not respect the signs are discarded, otherwise retained. We repeat the iteration until 1000 valid couples $\left(\Lambda^{*}, F^{*}\right)$ are extracted.

${ }^{11}$ In practice, for each admissible $\Lambda^{*}$, we compute the sum of the squared standardized distance of each element from the median value element-wise, and we then select the matrix $\Lambda^{*}$ for which this measure is minimized. This method ensures that the representative factors selected are orthogonal, which would not be the case if we just selected the median value of each element of the matrix $\Lambda^{*}$
} 
The graph shows that, not surprisingly, the information factor loads mainly on the 1-2 years segment of the yield curve, i.e. the horizon at which information stemming from the ECB is expected to matter most.
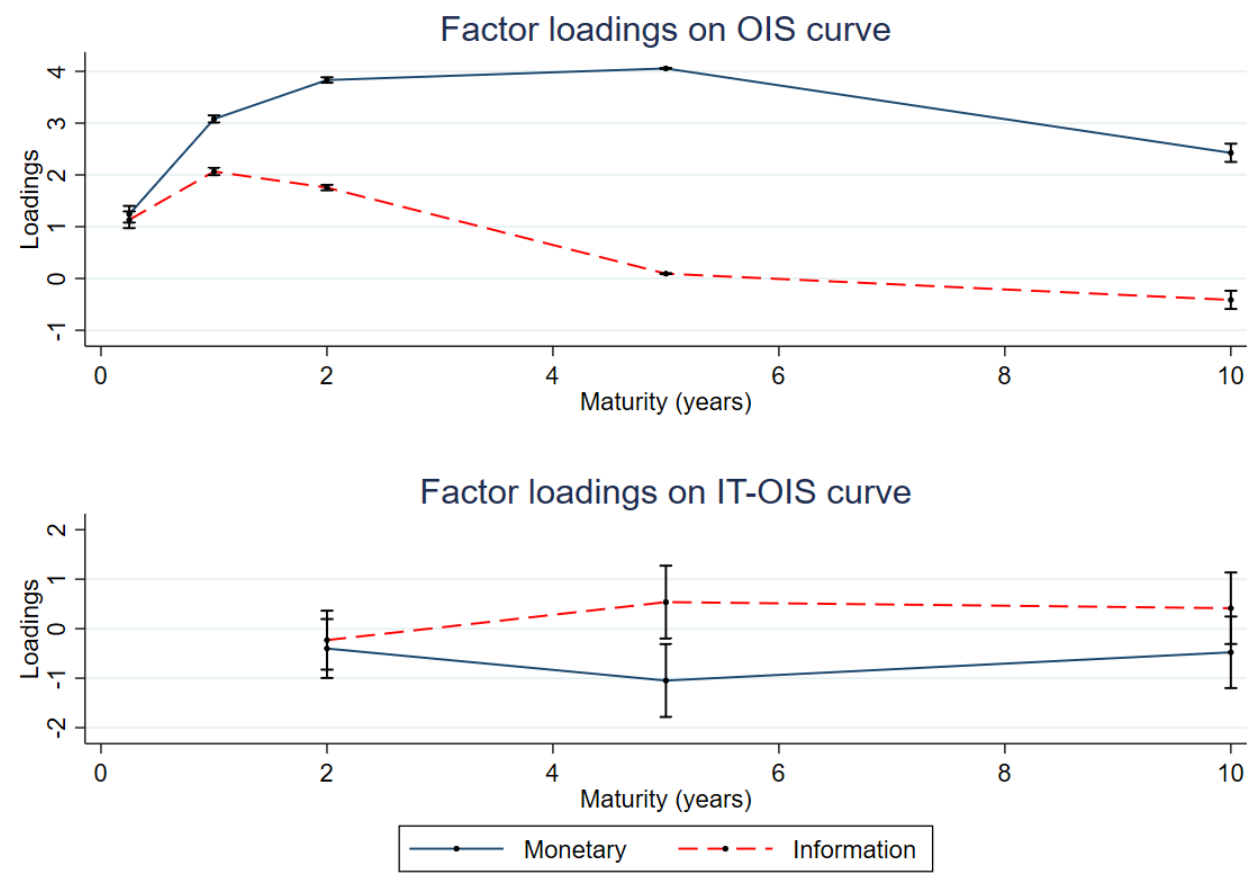

Figure 5: Monetary and information factor loadings obtained by regressing HF OIS and IT-OIS surprises on two factors. Vertical bars correspond to $95 \%$ confidence intervals.

The lower panel of Figure 5 plots the loadings estimated by regressing the HF variations of the spread IT-OIS at maturities $m=2,5,10$ years on the two MT factors $f_{m o n, t}^{M T}$ and $f_{i n f o, t}^{M T}$ with associated $95 \%$ confidence intervals. The loadings of the monetary factor on the OIS curve are positive (upper panel of the Figure), the loadings of the monetary factor on the spread IT-OIS curve are negative, i.e. the monetary factor generates a negative comovement of OIS rate and IT-OIS spreads. In other words, we still observe a negative correlation along the lines of Section 3 Furthermore, the estimated loadings of the information factor on the spread IT-OIS curve are never significant, i.e. the estimated information factor plays no role in describing HF variation of peripheral spreads around ECB press conferences. Overall, Figure 5 shows that accounting for the information shock alone (other than an unconventional monetary policy shock) does not explain some puzzling comovements in interest rate surprises. Next, we show that the introduction of a spread factor may help to reconcile the puzzle.

Three-factors setup. To introduce a third factor we enlarge the information set by augmenting the vector $\delta_{t}$ with the variations of the spreads $\Delta\left(I T_{m y, t}-O I S_{m y, t}\right)$ at maturities $m=2,5,10$ 
(years) observed around ECB press conferences. The sample period remains from January 2002 to June 2020. Thus, $\delta_{t}$ is now a $8 \times 1$ vector which reflects information from both the euro area yield curve and yield spreads, as captured by peripheral euro area countries, and the stock market. To keep the dimension of the system at a reasonable level, we consider Italy and Spain separately one at a time. Results discussed in this section refer to Italy and we confine the case of Spain to Appendix $\mathrm{C}$ as robustness check.

The (rotated) factor model is now specified as

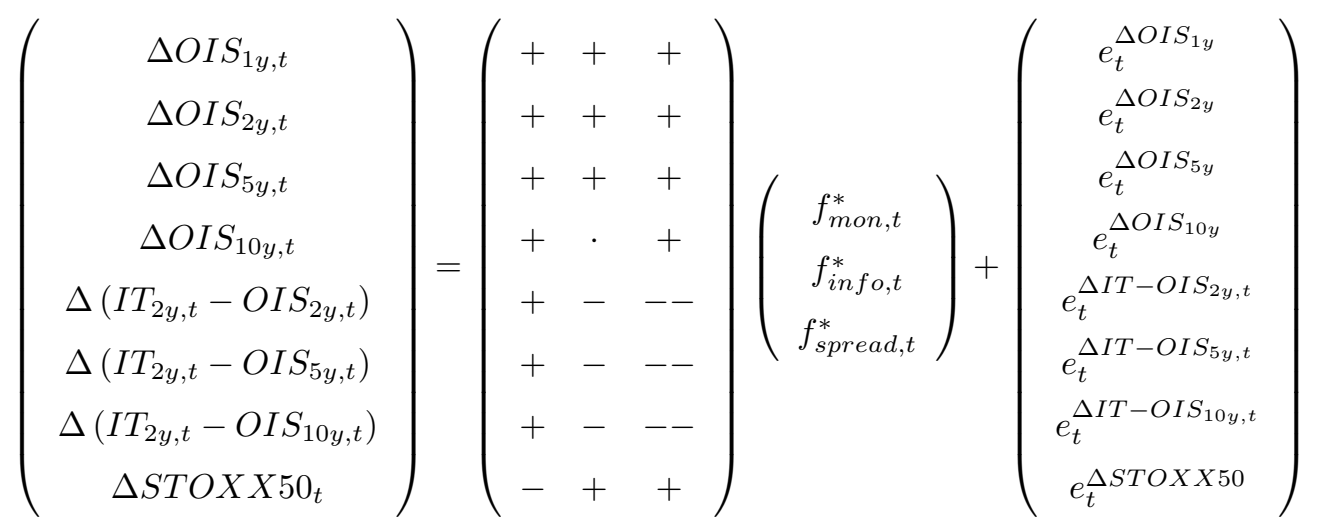

where $f_{\text {spread,t }}^{*}$ is interpreted as the spread factor, and $f_{m o n, t}^{*}$ and $f_{\text {info,t }}^{*}$ are as before. It can be noticed that aside from the presence of the symbol '--', whose meaning is explained below, in equation (4) the signs associated with the rotated factors $f_{\text {info,t }}^{*}$ and $f_{\text {spread,t }}^{*}$ are the same. Thus, in order to separate these two factors we complement the sign restrictions with additional 'narrative' restrictions ${ }^{12}$ Let $D_{1}=[2010-2014] \cup[2020]$ denote the set including all days in the specified years, and let $1_{D_{1}}(t)$ be the indicator function being equal to 1 when the day $t$ belongs to the set $D_{1}$ and zero elsewhere. First, we consider the restriction

$$
\operatorname{Var}\left\{f_{\text {spread }, t}^{*} 1\left(t \in D_{1}\right)\right\} \geq \tau \times \operatorname{Var}\left[f_{\text {spread }, t}^{*}\left(1-1\left(t \in D_{1}\right)\right)\right]
$$

which maintains that the variance of the spread factor during the period 2010-2014 of the debt crisis and in 2020 is at least $\tau>0$ times larger that the variance of the spread in all remaining periods. This restriction is justified by the following facts: (i) before 2010 the ECB was not essentially concerned with fragmentation risk and sovereign spreads were not an issue; (ii) since 2010 market pressures on peripheral debt grew considerably, culminating until the July 2012 "whatever it takes" speech by Mario Draghi; (iii) since 2014 peripheral debt has been less exposed to runs and the ECB has been mainly focused on implementing the first QE (the Asset Purchase Program), which, as explained above, is designed in a way that induces us to relate it mostly to the unconventional monetary policy rule, rather than to spread shocks; (iv) in 2020, with the pandemic outbreak, the role of the ECB in managing fragmentation risk (acknowledged with the implementation of the

\footnotetext{
${ }^{12}$ Similar strategies may be found e.g. in Antolín-Díaz and Rubio-Ramírez (2018) and Caggiano et al. (2021). Likewise, Swanson (2017) employs "variance restrictions" to identify a QE factor in the US; Furlanetto et al. (2019) employ restrictions on the relative magnitude of the response of certain variables in the SVAR to the shocks of interest, as we do for the spread shock; see Ludvigson et al. $(2020)$ for a general overview.
} 
PEPP) has become again paramount. The scalar parameter $\tau$ in (5) is calibrated to the value 1.7 in the empirical analysis, a value that can be given a statistical justification 13 Second, we impose that the loadings associated to the spread factor on the IT-OIS spread curve are larger (in absolute value) than the loadings of the information factor on the spread curve, restriction that we summarize with the symbol '--' in (4). This magnitude restriction provides a natural characterization of an instrument that should be used for the spread shock: the spread shock must affect sovereign spreads (in terms of impact magnitude) more than any other shock. The characterization in (4)-(5) of the spread shock complies with the main predictions of the stylized theoretical model sketched in Appendix A.1

The augmented factor model in (4) is estimated by maximum likelihood by the same algorithm sketched for the two-factor model, including now the additional constraints. Henceforth we denote with $\mathcal{F}_{t=1}^{T}$ the set containing the 1000 time series of factors $f_{t}^{*}=\left(f_{\text {mon, },}^{*}, f_{\text {info,t }}^{*}, f_{\text {spread,t }}^{*}\right)^{\prime}$, $t=1, \ldots, T$ that satisfy the sign and additional restrictions; further, we denote with $f_{t}^{M T}=$ $\left(f_{\text {mon }, t}^{M T}, f_{\text {info,t }}^{M T}, f_{\text {spread }, t}^{M T}\right)^{\prime}, t=1, \ldots, T$ three 'representative' factors selected from $\mathcal{F}_{t=1}^{T}$ using Fry and Pagan's (2011) median target (MT) method 14 Figure6 plots the series $f_{t}^{M T}=\left(f_{m o n, t}^{M T}, f_{\text {info }, t}^{M T}, f_{\text {spread,t }}^{M T}\right)^{\prime}$, $t=1, \ldots, T$.

The graph shows that one of the 'biggest' realizations of the information factor takes place in August 2011. Interestingly, this date is also identified by Jarocinski and Karadi (2020) as one of the leading examples of ECB's information effect. This evidence suggests that the three-factor decomposition does not necessarily undermine the role of the information factor, an issue that will be further confirmed below.

The upper panel of Figure 7 plots the estimated factor loadings obtained by regressing the quantities $\Delta O I S_{m y, t}, m=1,2,5,10$, on the three MT factors $f_{m o n, t}^{M T}, f_{\text {info,t }}^{M T}$ and $f_{\text {spread,t }}^{M T}$, with associated $95 \%$ confidence intervals. The lower panel plots the loadings estimated by regressing the quantities $\Delta I T_{t}-\Delta O I S_{m y, t}, m=2,5,10$ on the three MT factors, with associated $95 \%$ confidence intervals. The graph shows that the information factor is mostly connected to the OIS

${ }^{13}$ The threshold 1.7 in $\sqrt{5}$ can be justified by the following argument. In order to test the null-hypothesis

$$
H_{0}: \operatorname{Var}\left[f_{\text {spread,t }}^{*} 1_{D_{1}}\right]=\operatorname{Var}\left[f_{\text {spread }, t}^{*}\left(1-1_{D_{1}}\right)\right]
$$

against the one-sided alternative

$$
H_{1}: \operatorname{Var}\left[f_{\text {spread }, t}^{*} 1_{D_{1}}\right]>\operatorname{Var}\left[f_{\text {spread }, t}^{*}\left(1-1_{D_{1}}\right)\right]
$$

the test statistic is given by the ratio: $\frac{S_{D_{1}}^{2}}{S_{\left(1-D_{1}\right)}^{2}}$, where $S_{D_{1}}^{2}$ and $S_{\left(1-D_{1}\right)}^{2}$ denote the sample variances of the spread factor computed on the two sets of specified days, respectively. Under the null, the asymptotic distribution of this test statistic can be approximated as an $F\left(q_{1}, q_{2}\right)$ distribution, with $q_{1}$ corresponding to the number of elements included in $D_{1}$ minus 1 and $q_{2}$ to the number of elements included in the complementary set minus 1 (see e.g. (Snedecor and Cochran 1989)). In our framework, under the null hypothesis, we have an $F(51,142)$ distribution whose $1 \%$ critical value is roughly equal to 1.7 , i.e. the test rejects when $\frac{S_{D_{1}}^{2}}{S_{\left(1-D_{1}\right)}^{2}}>1.7$.

${ }^{14}$ The MT method appears a sensible choice for extracting a 'representative' vector from $\mathcal{F}_{t=1}^{T}$. We refer to Fry and Pagan (2011) for a thorough discussion of the MT method in sign-restrictions. 

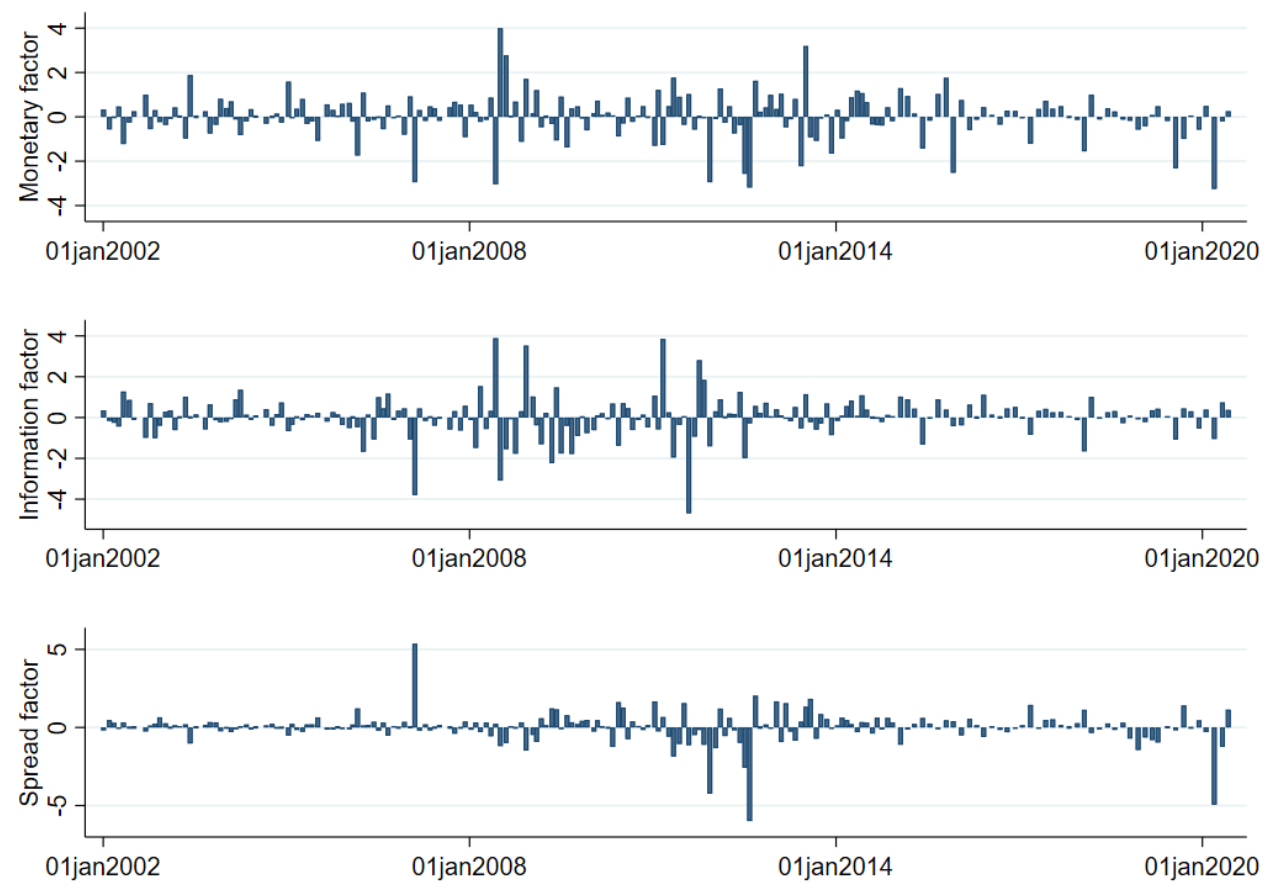

Figure 6: Estimated monetary, information and spread factors over the period January 2002-June 2020. Factors are standardized to have zero mean and unit variance.

curve at 1-2 years maturity while the spread factor at the 5-year maturity. As a consequence of the enlargement of the information set and the sign restrictions imposed, and differently from what we have documented in Figure 5 now the direction through which the monetary factor loads on the OIS and IT-OIS curves is the same.

Table 1 illustrates how the variability of the components in the vector $\delta_{t}$ can be ascribed to each of the three MT factors. Each row of Table 1 refers to simple regressions where each component of $\delta_{t}$, say $\delta_{i, t}$ (see first column in the table), is regressed on the three MT factors $f_{t}^{M T}=\left(f_{\text {mon }, t}^{M T}, f_{\text {info }, t}^{M T}, f_{\text {spread }, t}^{M T}\right)^{\prime}$, i.e.

$$
\delta_{i, t}=\lambda_{1} f_{m o n, t}^{M T}+\lambda_{2} f_{\text {info }, t}^{M T}+\lambda_{3} f_{\text {spread }, t}^{M T}+\text { error }_{i, t} \quad, \quad t=1, \ldots, T
$$

The second column in Table 1 sketches the $R^{2}$ of the various regressions and the last three columns attribute the overall variability to the three factors using a Shapley $R^{2}$ decomposition. The overall $R^{2}$ is always very high for OIS rates and IT-OIS spread while is more modest, not surprisingly, for the stock index. The contribution of the information factor along the OIS yield curve is extremely variable and declines over maturity. The opposite is true for the spread factor which contributes to the regression variability with a share which increases with maturity.

Instead, Figure 8 devotes attention to four relevant dates. The graph plots some HF surprises $\delta_{i, t}$ observed in the day $t=\bar{t}$, along with the estimated quantities $\hat{\lambda}_{1} f_{m o n, \bar{t}}^{M T}, \hat{\lambda}_{2} f_{\text {info, } \bar{t}}^{M T}$ and 

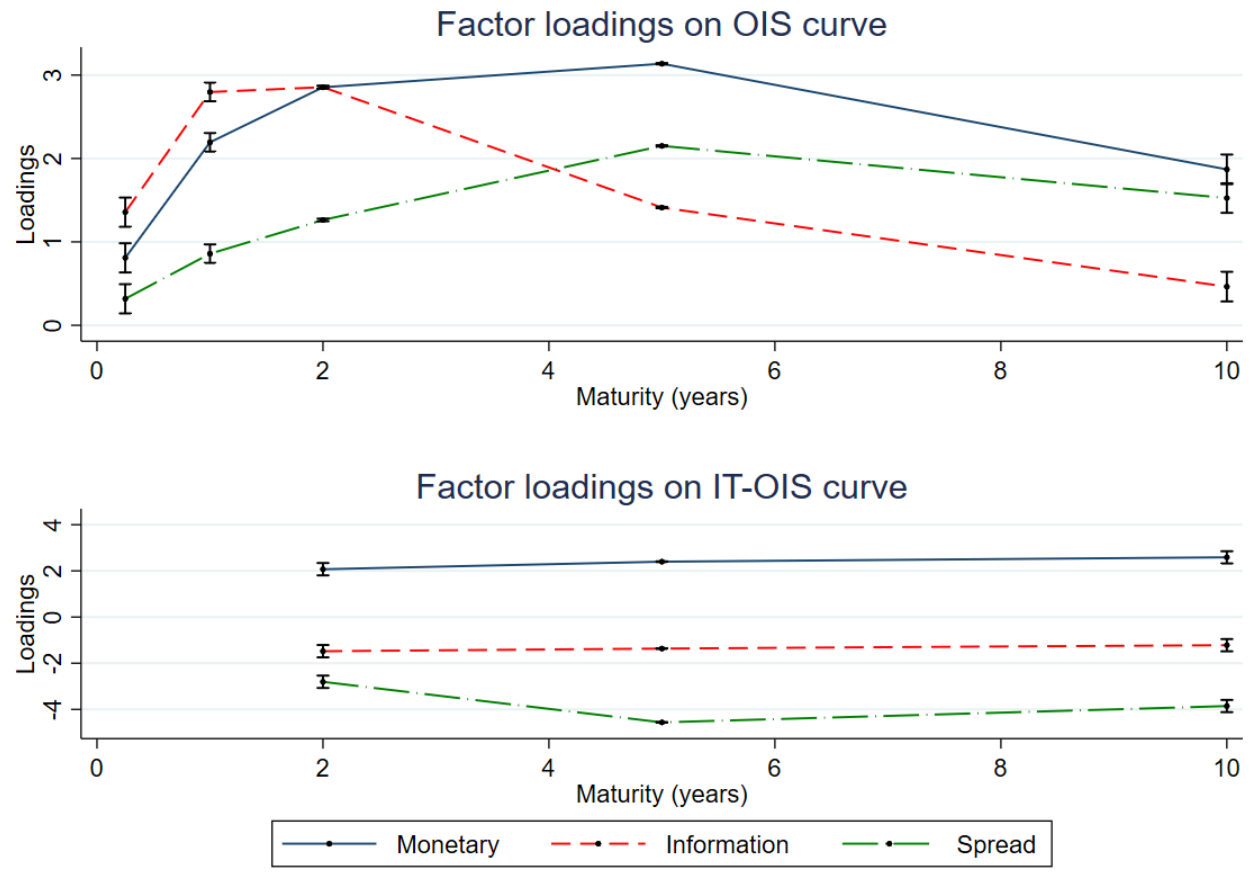

Figure 7: Monetary, information and spread factor loadings obtained by regressing HF OIS and IT-OIS surprises on three factors. Vertical bars correspond to $95 \%$ confidence intervals.

$\hat{\lambda}_{3} f_{\text {spread }, \bar{t}}^{M T}$, obtained in correspondence of those selected particular days. August 4, 2011 is interesting for the reasons just mentioned: most of the decrease in the OIS rates, especially at 1-2 years maturity, is attributable to an information effect which also drives up the spread IT-OIS. August 2, 2012 refers to the OMT announcement, which is followed by the biggest recorded increase in the IT-OIS spread (more than 40 basis points). Financial markets were in fact initially disappointed by the announcement, not fully understanding OMT's implications. In the following days the trend was reverted and sovereign spreads started to decrease significantly. Nonetheless, this event provides a good example of a realization of a spread shock, which is the main responsible for variations observed on that date. The same reasoning applies to March 12, 2020. Finally, the date of January 22, 2015 shows variations on the day of the QE announcement (the APP). Here the monetary factor gets the lion share, driving down OIS rates and the IT-OIS spread. Nonetheless, a significant spread factor is estimated to partially counterbalance the decrease in the IT-OIS spread and further driving down OIS rates. On the same date also a significant information effect is estimated, driving up OIS rates.

\section{Three shocks identification}

In this section we move to the second-step of our empirical identification approach, i.e. we use elements extracted from the set of admissible factors discussed in the previous section, $\mathcal{F}_{t=1}^{T}$, as 


\begin{tabular}{l|c|ccc}
\hline & $R^{2}$ & Monetary factor & Spread factor & Information factor \\
\hline$\Delta$ OIS 1y & $95.6 \%$ & $36 \%$ & $5.5 \%$ & $58.5 \%$ \\
$\Delta$ OIS 2y & $99.9 \%$ & $45.5 \%$ & $8.9 \%$ & $45.6 \%$ \\
$\Delta$ OIS 5y & $99.9 \%$ & $59.8 \%$ & $28.1 \%$ & $12.1 \%$ \\
$\Delta$ OIS 10y & $79.4 \%$ & $57.9 \%$ & $38.5 \%$ & $3.6 \%$ \\
\hline$\Delta$ IT-OIS 2y & $80 \%$ & $29.9 \%$ & $54.8 \%$ & $15.2 \%$ \\
$\Delta$ IT-OIS 5y & $99.9 \%$ & $20.2 \%$ & $73.2 \%$ & $6.6 \%$ \\
$\Delta$ IT-OIS 10y & $86.9 \%$ & $29.1 \%$ & $64.5 \%$ & $6.4 \%$ \\
\hline$\Delta$ STOXX50 & $33.2 \%$ & $58.1 \%$ & $32.3 \%$ & $6.6 \%$ \\
\hline
\end{tabular}

Table 1: Percentage of the variance of HF surprises explained by the three factors. The first column reports the overall $R^{2}$. The last three columns report Shapley $R^{2}$ decomposition.

external instruments in a proxy-SVAR estimated on daily data. Our objective is to point-identify the dynamic causal effects produced by three monetary policy shocks on financial-type variables like the stock market, an inflation-linked swap rate and the Eur-Usd exchange rate.

Proxy-SVAR setup. Our starting point is the reduced form VAR system given by the specification

$$
\Pi(L) y_{t}=\mu+\gamma t+u_{t}, \quad t=1, \ldots, T
$$

where the time index $t$ refers to days, $y_{t}$ is the vector of endogenous variables, $\Pi(L)$ is the autoregressive polynomial, $\mu$ is a constant, $\gamma$ are parameters associated with a linear trend that might characterize some of the variables in $y_{t}$, and $u_{t}$ is the vector of reduced-form innovations with assumed time-invariant covariance matrix, $\Sigma_{u}$. We decompose $y_{t}$ into two parts, $y_{t}=\left(r_{t}^{\prime}, x_{t}^{\prime}\right)^{\prime}$, where $r_{t}$ contains the variables associated with the structural shocks we are interested to identify, hereafter denoted policy indicators, and $x_{t}$ contains the response variables. The variables included in $r_{t}$ and $x_{t}$ in the empirical analysis are specified below. The VAR innovations $u_{t}$ can be decomposed accordingly, i.e. $u_{t}=\left(u_{r, t}^{\prime}, u_{x, t}^{\prime}\right)^{\prime}$.

In a 'standard' SVAR context, the reduced from innovations are linked to the structural shocks by the expression:

$$
u_{t}=C \varepsilon_{t}
$$

where $C$ is the matrix of coefficients that capture the instantaneous impact of the structural shocks $\varepsilon_{t}$ on the variables. In a proxy-SVAR setup, the focus is on the identification of a subsets of the structural shocks potentially embedded in $\varepsilon_{t}$, say $\varepsilon_{r, t}$, regardless of the non-instrumented structural shocks in $\varepsilon_{x, t}$; note that $\varepsilon_{t}=\left(\varepsilon_{r, t}^{\prime}, \varepsilon_{x, t}^{\prime}\right)$. With this shock decomposition, the relation in (8) can be restated as

$$
u_{t}=C_{r} \varepsilon_{r, t}+C_{x} \varepsilon_{x, t}
$$



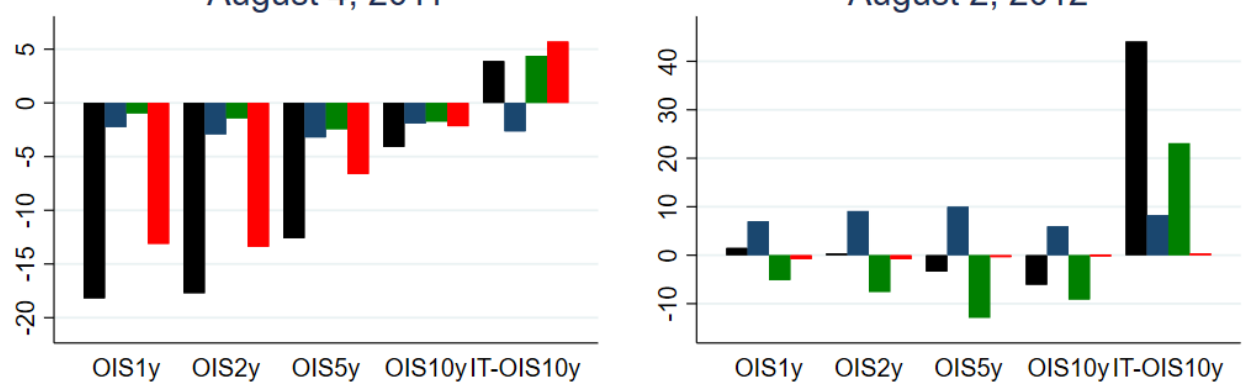

January 22, 2015

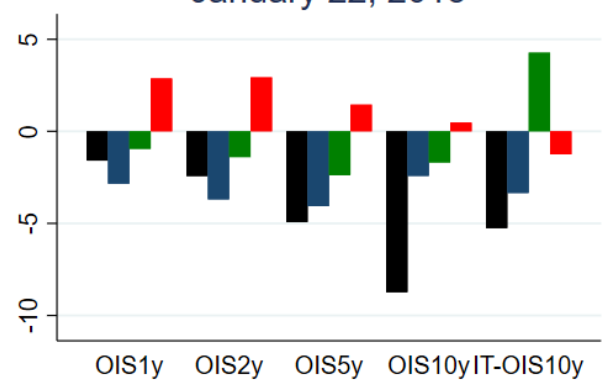

March 12, 2020
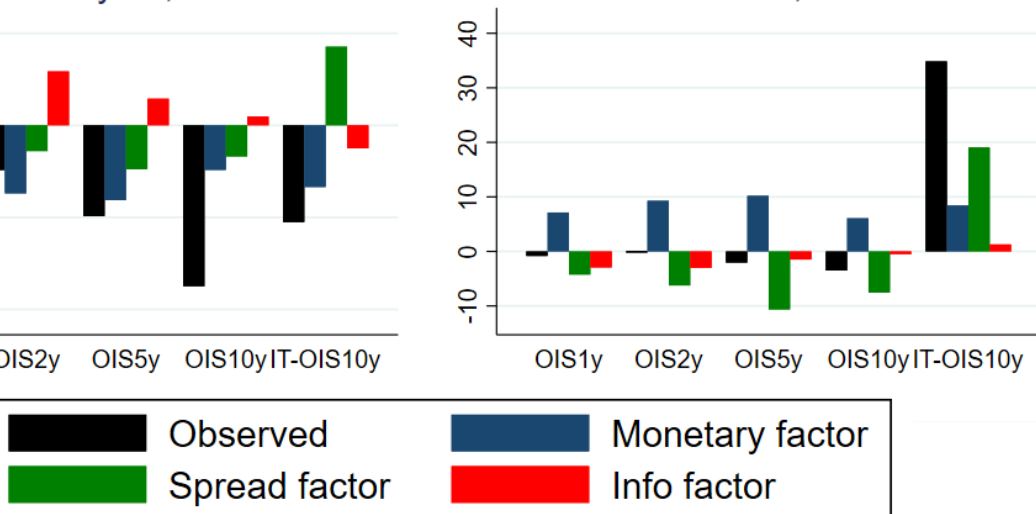

Figure 8: Black bars correspond to actual HF surprises at four particular dates $\left(\delta_{i, \bar{t}}\right)$. Blue, green and red bars correspond to the quantities $\hat{\lambda}_{1} f_{m o n, \bar{t}}^{M T}, \hat{\lambda}_{2} f_{\text {info, } \bar{t}}^{M T}$ and $\hat{\lambda}_{3} f_{\text {spread, } \bar{t}}^{M T}$, respectively, see equation 6 in the text.

hence the matrix $C_{r}$ collects the on-impact responses of the variables to the target structural shocks $\varepsilon_{r, t}$. The impulse response functions that track the impact of the target structural shocks on the variables are therefore given by

$$
\frac{\partial y_{t+h}}{\partial \varepsilon_{r, t}}=\left(S A^{h} S^{\prime}\right) C_{r} \quad, \quad h=1, \ldots, h_{\max }
$$

where $A$ is the VAR companion matrix, $S$ is a selection matrix such that $S S^{\prime}=I$, and $h_{\max }$ is the maximum time horizon considered. Thus, the knowledge of the parameters in $C_{r}$ jointly with the reduced form VAR dynamics in $\Pi(L)$ (compacted in the companion matrix $A$ ) allow us to recover the dynamic causal effects produced by the target shocks in $\varepsilon_{r, t}$.

Let $k$ be the number of structural shocks in $\varepsilon_{r, t}$. In our leading case, $\varepsilon_{r, t}$ is a three-dimensional vector that collects the monetary policy shock, the information shock and the spread shock, respectively, i.e. $k=3{ }^{15}$ Let $z_{t}$ be the $k \times 1$ vector of proxies (external variables) used to identify the structural shocks $\varepsilon_{r, t}$ (i.e. the parameters in $C_{r}$ ), where recall that $z_{t}$ is extracted from the set of admissible factors $\mathcal{F}_{t=1}^{T}$ discussed in the previous section. The proxies (or instruments) $z_{t}$ must

\footnotetext{
${ }^{15}$ For comparative purposes, in Appendix ?? we also consider the 'two-shocks' setup where $\varepsilon_{r, t}$ is $2 \times 1$ and collects the monetary policy shock and the information shock alone.
} 
satisfy the two conditions

$$
\begin{aligned}
& E\left(z_{t} \varepsilon_{r, t}^{\prime}\right)=\phi, \operatorname{rank}[\phi]=k \\
& E\left(z_{t} \varepsilon_{x, t}^{\prime}\right)=0
\end{aligned}
$$

known as relevance and exogeneity (orthogonality) conditions, respectively. $\phi$ is the matrix of relevance parameters and connects the proxies to the target shocks up to measurement errors; $\phi$ must be full-column rank for the proxies carrying strong and independent information on the target structural shocks. The second condition maintains that the proxies $z_{t}$ are exogenous (orthogonal) to the non-instrumented structural shocks, $\varepsilon_{x, t}$. A convenient way to summarize the two key properties of the proxies is to refer to the expression

$$
z_{t}=\phi \varepsilon_{r, t}+\sigma_{z} \omega_{t}
$$

which links $z_{t}$ to the target structural shocks $\varepsilon_{r, t}$ by the matrix $\phi$, up to a measurement error term $\sigma_{z} \omega_{t}$. The normalized measurement error $\omega_{t}$ is modeled as a zero-mean vector with covariance matrix $\sigma_{z} \sigma_{z}^{\prime}$ and is assumed to be orthogonal to all structural shocks of the system.

Estimation challenges and solutions. Two main challenges characterize the estimation of the proxy-SVAR obtained from the combination of (9) with (11). First, it is necessary to select a $k \times 1$ vector of proxies $z_{t} \equiv f_{t}^{*}$ from the set of admissible factors $\mathcal{F}_{t=1}^{T}$. Second, given the multiple shocks setup $(k>1)$, it is necessary to impose additional restrictions (other than the instruments) on the model to obtain the impulse response functions in (10). From results in Angelini and Fanelli (2019), it follows that at least $\frac{1}{2} k(k-1)$ additional restrictions (without counting 'unit-effect' normalizations) are needed for identification.

We solve the first issue as follows. We consider the vector of MT factors $z_{t} \equiv f_{t}^{M T}=$ $\left(f_{m o n, t}^{M T}, f_{\text {info,t }}^{M T}, f_{\text {spread }, t}^{M T}\right)^{\prime}$ (see Figure 6) as 'representative' of the set $\mathcal{F}_{t=1}^{T}$ and estimate the proxySVAR using these instruments by the classical minimum distance (CMD) approach summarized below. Doing so, we obtain point estimates of the impulse responses 10 and quantify the uncertainty surrounding these estimates by the moving block bootstrap (MBB) extended by Jentsch and Lunsford (2019a) and Jentsch and Lunsford (2019b) to proxy-SVARs. However, in order to also account for the uncertainty stemming from the selection of factors from the set $\mathcal{F}_{t=1}^{T}$, we also estimate all 1000 proxy-SVARs obtained in correspondence of all possible choices of instruments $z_{t} \equiv f_{t}^{*}=\left(f_{\text {mon }, t}^{*}, f_{\text {info,t }}^{*}, f_{\text {spread }, t}^{*}\right)^{\prime}$ in the admissible set $\mathcal{F}_{t=1}^{T}$. This produces 1000 estimates of the impulse responses of interest from which we can derive quantiles interpretable as measures of 'across models' uncertainty. We can therefore quantify two dimensions that characterize the uncertainty surrounding the estimated dynamic causal effects jointly produced by the three shocks: the statistical uncertainty captured by MBB confidence intervals; the model uncertainty that arises from the fact that there are potentially many eligible proxies that can instrument the three structural shocks. 
We solve the second issue by estimating the proxy-SVAR(s) by the CMD estimation method developed in Angelini and Fanelli (2019). The advantage of Angelini and Fanelli's (2019) approach lies in the flexibility it provides in the management of the additional restrictions necessary to pointidentify the proxy-SVAR other than the proxies. To see this, observe that by properly combining (9) and (11), one derives the moment conditions:

$$
\begin{aligned}
\Sigma_{u, z} & =\phi C_{r}^{\prime} \\
\Omega & =\phi \phi^{\prime}
\end{aligned}
$$

which are at the basis of proxy-SVAR estimation. In $(12)-13), \Sigma_{z, u}=E\left(z_{t} u_{t}^{\prime}\right)$ is the (reduced form) covariance matrix that links the VAR innovations with the proxies, and $\Omega=\Sigma_{z, u} \Sigma_{u}^{-1} \Sigma_{u, z}$ is a function of the reduced form covariance parameters in $\Sigma_{z, u}$ and $\Sigma_{u}$, respectively. The equations in 12]-13 connect the reduced form parameters contained in $\Sigma_{u, z}$ and $\Omega$ to the structural parameters contained in the matrix $\left(C_{r}^{\prime} \vdots \phi^{\prime}\right)^{\prime}$ and that we collected for simplicity in the vector $\theta$. Since $\Sigma_{u, z}$ and $\Omega$ can be estimated consistently from the data under fairly general conditions, the CMD estimate of $\theta$ can be obtained from the solution to the problem:

$$
\min _{\theta}\left\{\left(\begin{array}{c}
\operatorname{vec}\left(\hat{\Sigma}_{u, z}-\phi C_{r}^{\prime}\right) \\
\operatorname{vec}\left(\hat{\Omega}-\phi \phi^{\prime}\right)
\end{array}\right)^{\prime} W_{T}\left(\begin{array}{c}
\operatorname{vec}\left(\hat{\Sigma}_{u, z}-\phi C_{r}^{\prime}\right) \\
\operatorname{vec}\left(\hat{\Omega}-\phi \phi^{\prime}\right)
\end{array}\right)\right\}
$$

where $\hat{\Sigma}_{u, z}$ and $\hat{\Omega}$ are consistent estimates of $\Sigma_{z, u}$ and $\Omega$, and $W_{T}$ reads as a weighting matrix with a role similar to that weighting matrices have in GMM estimation, see Angelini and Fanelli (2019). The minimazion problem 14 is carried out by imposing the $\frac{1}{2} k(k-1)=3$ additional restrictions necessary for identification. The advantage of framing the estimation problem of the proxy-SVAR in the context (12)-14 is that the additional restrictions can be placed on the onimpact coefficients in $C_{r}$ alone, on the relevance parameters in $\phi$ alone, or can be distributed across both $C_{r}$ and $\phi$. Given the daily data framework, it is problematic to take a stand on which are the variables that do not respond instantaneously (within the day) to the three structural shocks in $\varepsilon_{r, t}$, hence we prefer to confine the additional restriction in the matrix of relevance parameters $\phi$ alone, leaving the on-impact parameters in $C_{r}$ unrestricted.

Empirical specification and results. In the 'three-shocks' specification, $y_{t}=\left(r_{t}^{\prime}, x_{t}^{\prime}\right)^{\prime}$ is $6 \times 1$. The vector of policy indicators $r_{t}$ is $3 \times 1$ and contains the 5 -year and the 1 -year sovereign AAA-rated yields constructed by the ECB by averaging yields from euro area sovereign rates with triple A rating and the 10-year spread IT-OIS. The vector of response variables, $x_{t}$, contains the $\log$ of the STOXX50 index, the 2-year inflation-linked swap rate (a proxy of inflation expectations) and the log of the EURO-USD exchange rate. These variables are similar to those used in Altavilla et al. (2019). The matrix of relevance parameters $\phi$ in the estimation problem defined by (12)-(14) is specified upper triangular so the system accommodates the additional restrictions necessary for identification. The resulting proxy-SVAR is exactly identified and can be taken to 
the data. Observe that given the instruments $z_{t} \equiv f_{t}^{M T}=\left(f_{m o n, t}^{M T}, f_{\text {info,t }}^{M T}, f_{\text {spread,t }}^{M T}\right)^{\prime}$ and $[11)$, the upper triangular structure of the matrix $\phi$ means that the monetary factor is allowed to convey information on the information and spread shocks other than the monetary shocks; likewise, the information factor is allowed to convey information on the spread shock other than the information shock. As detailed below, our main results are robust to specifying $\phi$ lower triangular.

The proxy-SVAR is estimated on the period 15-08-2005-30-06-2020 16 The reduced form system (7) includes six lags (selected by minimizing the AIC criterion), a constant and a deterministic linear trend.

The columns (a), (b) and (c) in Figure 9 plot the estimated impulse response functions over an horizon of 1000 days (corresponding to roughly three years) with associated 68\%-and 90\%-MBB confidence intervals. All target shocks have been normalized to decrease their respective policy indicators by 10 basis points. For comparative purposes, the columns (d) and (e) in Figure 9 plot the impulse response functions that obtains when the proxy-SVAR is estimated by considering two-shocks only, i.e. without the spread shock 17

We remark, from Figure 9, the effect that the monetary shock exerts on the risk premium on Italian bonds. This shock has been normalized to reduce the 5 -year risk-free rate by 10 basis points on-impact, hence it reads as an expansionary shock. In the two-shock specification the result is puzzling: a decrease in the risk-free rate leads to a slight increase in the periphery risk premium. This phenomenon is not observed in the three-shocks model where we find a strong pass-through of the expansionary monetary policy action to the Italian risk premium. The negative response of the IT-OIS spread is sizable (15 basis points at the peak) and persistent. The identified monetary shock in the three-shocks specification produces reasonable responses of the other variables relative to the two-shocks specification. The stock market index increases significantly, where the increase is barely significant in the two-shocks model. The EUR-USD exchange rate depreciates in both specifications; inflation expectations slightly increase in the short term when considering $68 \%$ confidence bands. This finding is at odds with results from the two-shocks scenario where no significant reaction is detected.

The information shock is normalized in Figure 9 to lower the 1-year risk-free yield by 10 basis points, hence it can be regarded as a 'contractionary' one in the sense that one expects a worsening of agents' expectations about future economic outlook in response to it. The 5-year rate response decreases as well but the effect is much weaker ( 5 basis points peak decrease). The information shock increases the Italian risk premium though the effect is not significant. Inflation expectations seem to react significantly only to the information shock: we estimate a 10 basis points decrease on-impact.

The identified spread shock is normalized in Figure 9 to lower the spread IT-OIS by 10 basis

\footnotetext{
${ }^{16}$ OIS rates at long maturities are not available before 15-08-2005.

${ }^{17}$ The estimation approach followed for the 'two-shocks' proxy-SVAR is the same as the one described above; details can be found in Appendix B
} 
points. It is seen that the estimated decrease is persistently significant and lasts about 200 days. Furthermore, risk-free yields increase in response to the spread shock. The increase is modest but significant: approximately 2 basis points for the 1-year yield, and 3-basis points for the 5-year one. The larger increase observed in the 5-year yield suggests that the expansionary spread shock makes the risk-free yield curve steeper. The increase in risk-free rates is quite persistent lasting about 200 days. The expansionary spread shock is also accompanied by an increase in stock market prices and an appreciation of the EUR-USD nominal exchange rate. Inflation expectations slightly increase, though not significantly. Overall, the dynamic causal effects estimated for the spread shock do not appear at odds with the predictions of the stylized model considered in Section 4 (see also Appendix A.1.

To check the sensitivity of the responses in Figure 9 to choice of the MT factors as proxies for the three monetary shocks, we complement our analysis with a measure of 'across models' uncertainty. We estimate all 1000 proxy-SVARs obtained by selecting the proxies from the admissible set $\mathcal{F}_{t=1}^{T}$ and build quantiles from the resulting IRFs. Figure 10 contrasts the responses in the columns (a)-(b)-(c) of Figure 9 with the 16-84 quantiles that reflect the model uncertainty arising from the selection of proxies from the admissible set. The graph shows that, overall, the responses estimated by the MT factors and the associated uncertainty captured by the MBB tend to line up with the 16-84 quantiles that reflect model uncertainty.

Finally, we re-estimated the proxy-SVAR by changing the structure of the matrix of relevance parameters $\phi$ from upper to lower triangular. We do not detect sizable differences relative to what reported in Figure $9^{18}$

The responses of the target variables to the newly identified spread shock are new in the literature and reveal the role the ECB plays in the management of fragmentation risk in the euro area. Figure 9 shows that the central bank's concern for fragmentation risk can be beneficial also for the private banks of 'core' euro area countries whose profits strongly depend on long term risk free yields which are permanently set at very low (even negative) values, but are moved upward by policies that reduce fragmentation risk, i.e. expansionary spread shocks.

\section{$7 \quad$ Macroeconomic effects}

In the previous section we have assumed that the data generating process, approximated by a proxySVAR, operates at the daily frequency. This hypothesis prevented us from focusing on the effects

\footnotetext{
${ }^{18}$ We observe few differences between the estimated impulse responses in the two different specifications. In the lower triangular $\phi$ specification, the information shock affects the Italian risk premium more significantly and affects more strongly the risk free rate at 5-year maturity. The spread shock on the contrary moves the risk-free yield curve only at 5-year maturity while the 1-year yield does not move. The upper triangular $\phi$ specification provides impulse responses more in line with a clear distinction between the information and the spread shocks, especially because the information shock does not move the peripheral risk premium, i.e. there is less of a worry that the two estimated shocks are both convolution of the underlying true information and spread shocks.
} 
that the three identified monetary shocks exert on variables that capture real economic activity, systemic risk and financial distress, which are typically not available at daily frequency. In this section we quantify the impact of the three monetary policy shocks on macroeconomic variables of interest, giving emphasis to the effects of the spread shock which is meant to be a synthetic measure of the policies implemented by the ECB to control the risk premium on peripheral countries debt.

To move the empirical analysis from the daily to the monthly data frequency reducing the risk of losing relevant information 19 we follow a strategy recently discussed in Alessandri et al. (2021) with an important difference. After converting the three proxies built in the previous sections from the daily to the monthly frequency through averaging, we quantify the dynamic causal effects produced by the three monetary policy shocks on real economic activity, systemic risk and financial distress by the so-called local projection instrumental variable approach (LP-IV). To do so, we use our three proxies as external instruments for the underlying latent shocks, see Stock and Watson (2018) 20 In this respect, our approach is consistent with Gertler and Karadi (2015), in the sense that the proxies build in the daily data framework are averaged at the monthly frequency: each observation of the proxy used for a shock is assumed to last 30 days or less if a press conference is held before.

We are interested in the following seven endogenous variables observed at monthly frequency: the 5-year and the 1-year sovereign AAA-rated euro area yields, the 10-year spread IT-OIS, the $\log$ of the STOXX50 index, the log of the euro area industrial production index (excluding construction), the log of the HICP index, and the CISS index of systemic risk and financial distress produced by the ECB. Variables available at higher frequency are transformed to monthly by averaging. The time index $t=1, \ldots, T$ now refers to months. The seven variables of interest are collected in the vector $y_{t}=\left(y_{1, t}, y_{2, t}, \ldots, y_{7, t}\right)^{\prime}$, where each $y_{i, t}, i=1, \ldots, 7$ is a scalar. With $r_{t}$ we still indicate the $k \times 1$ vector of policy indicators discussed in the previous section, the main difference being that we now consider monthly averages of daily counterparts. Thus, in the following, $r_{j, t}$ denotes the $j$-th element of $r_{t}, j=1,2,3$. Notice that, by construction, $y_{i, t} \equiv r_{i, t}$ for $i=1,2,3$. Again, $z_{t} \equiv f_{t}^{M T}=\left(f_{\text {mon }, t}^{M T}, f_{\text {info,t }}^{M T}, f_{\text {spread }, t}^{M T}\right)^{\prime}$ is the vector of proxies extracted by the MT method from the identification set built in Section 5 and then converted to the monthly frequency.

\footnotetext{
${ }^{19}$ As detailed in Foroni and Marcellino (2016), Foroni et al. (2019), estimating a low-frequency structural time series model obtained by aggregating data stemming from an HF data generating process may create important problem for identification. Alessandri et al. (2021) rationalize the practice of using daily data to identify structural shocks and then averaging them in estimation exercises carried out at the monthly frequency.

20 Plagborg-møller and Wolf (2021) have shown that, conceptually, and in population, local projections and VARs estimate the same impulse responses and that the difference between the local projection and VAR impulse response estimators converges to zero asymptotically in sample when large lag lengths are used. As practitioners know, despite these equivalences, differences between the local projection and VAR impulse response estimators can be substantial in finite samples, where it frequently happens that the models fitted to the data involve a relatively small number of lags. Thus, we prefer to rely on the the LP-IV approach which appears robust, in finite samples, to a number of issues discussed in detail in Stock and Watson (2018).
} 
The LPs we take to the data are given, for $h=0,1, \ldots, h_{\max }$, by the regressions

$$
y_{i, t+h}=\alpha_{i, h}+\gamma_{i, h} t+\beta_{i, j, h} r_{j, t}+\underbrace{\sum_{\ell=1}^{p} \pi_{\ell, h}^{\prime} y_{t-\ell}+\sum_{s=1}^{q} \varphi_{s, h}^{\prime} z_{t-s}}_{\text {controls }}+\eta_{i, j, t+h}
$$

where $h_{\max }$ is the maximum time horizons, $\alpha_{i, h}$ are constants, $\gamma_{i, h}$ are coefficients associated with a linear trend, $\beta_{i, j, h}$ is the parameter that captures the impact of the policy indicator on the target variable after $h$ periods; $\eta_{i, j, t+h}$ are projection errors. The projections include the following controls: $p$ lags of the seven variables in $y_{t}$ and $q$ lags of the three proxies in $z_{t}{ }^{21}$ It is maintained that $\beta_{i, i, 0}=1$ in 15 for $i=1,2,3$. As observed, $\beta_{i, j, h}$ picks out the impact of the policy indicator $r_{j}$ on the variable $y_{i, t+h}$ and is estimated by using the proxy $z_{j, t}$ as an instrument for the policy indicator $r_{j, t}$. The equations are estimated up to $h_{\max }=36$ months computing Newey-West-HAC standard errors. First-stage regressions tend to rule out serious weak-instrument issues: the robust F-statistics are equal to 17.6 for the monetary shock, 24.9 when the information shock and 15.9 for the spread shock, respectively.

Figures 11, 12, 13 show the estimated impulse responses to the monetary, information and spread shocks, respectively. All three-shocks are normalized to lower the instantaneous impact on the associated policy indicator by 10 basis points.

As shown in Figure 11, the monetary shock causes a persistent decline in risk-free rates both at 1-year and 5-year maturity but does not impact significantly on the IT-OIS spread. Quite strikingly, the stock market declines and recovers only after 2 years while the industrial production index does not tend to react at all. Consumer prices exhibit a striking decline after 20 months but with a small size effect (more or less $-0.2 \%$ ). These results confirm the difficulty encountered in the literature to detect strong expansionary effects of unconventional monetary policies in the euro area.

The effects produced by the information shock are summarized in Figure 12 The observed decline in the risk-free rates, which lasts only few months, are not accompanied by significant effects in the other target variables. This evidence suggests that the role of the information shock in the euro area must be considered jointly with the spread shock, whose impact is plotted in Figure 13 It is seen that the negative response of the spread IT-OIS to the spread shock is significant and lasts almost half an year. This decline is accompanied by an increase in both the 1-year and 5-year risk-free rates. The stock market response produces and increases of the STOXX50 index by roughly $2 \%$ on-impact, and also the industrial production index increases on-impact by roughly $1 \%$, though the effect is barely significant. The response of consumer does not appear significant. Though the estimated impacts produced by the spread shock are not always strong in a statistical sense, the local projection analysis seems to support the predictions of our stylized model of multiple equilibria outlined in Appendix A: the reduction in the Italian sovereign spread

\footnotetext{
${ }^{21}$ The way in which we aggregate the factors from the daily to the monthly frequency may generate autocorrelation mechanisms that we control for by considering also lags of the proxies.
} 
due to the spread shock is expansionary (stock prices, industrial production and consumer prices increase) and induces an increase in the risk-free yield curve.

\section{Conclusion}

The conduct of monetary policy in the euro area is complicated by the fact that there are 19 sovereign bond markets which makes fragmentation risk a concern for policy makers. The years of the sovereign debt crisis and the recent global crisis due to the Covid-19 pandemic have made it clear that the ECB plays a crucial role in stabilizing economic activity by unconventional tools which include, among others, a 'concern' on sovereign spreads. HF interest rate surprises reflect the role the ECB plays in the face of fragmentation risk and this paper has taken an explicitly stand on this idea.

Focusing on HF comovement of long term OIS rates and euro area peripheral countries risk premia around ECB press conferences, we detect a puzzle: the expected positive correlation among the two financial variables is often not seen in the data. The puzzle cannot be resolved by solely considering the joint effects of a monetary shock and a central bank information shock. We introduce a third shock, called spread shock, which can be rationalized assuming that the ECB directly affects risk premia of peripheral countries to control for fragmentation risk. The spread shock, identified by a novel methodology which combines sign and narrative restrictions with the 'external instruments' methodology, synthesizes all policies/announcements by the ECB aimed at reducing pressures on the risk premia on peripheral countries.

We have shown that the spread shock helps to solve the aforementioned puzzle and improves the overall identification of unconventional monetary policy in the euro area. Empirical result suggest that the spread shock produces effects on macroeconomic and financial variables that are in line with the predictions of our reference stylized model. Importantly, we find that the spread shock is complementary, not substitute, to the information shock. 

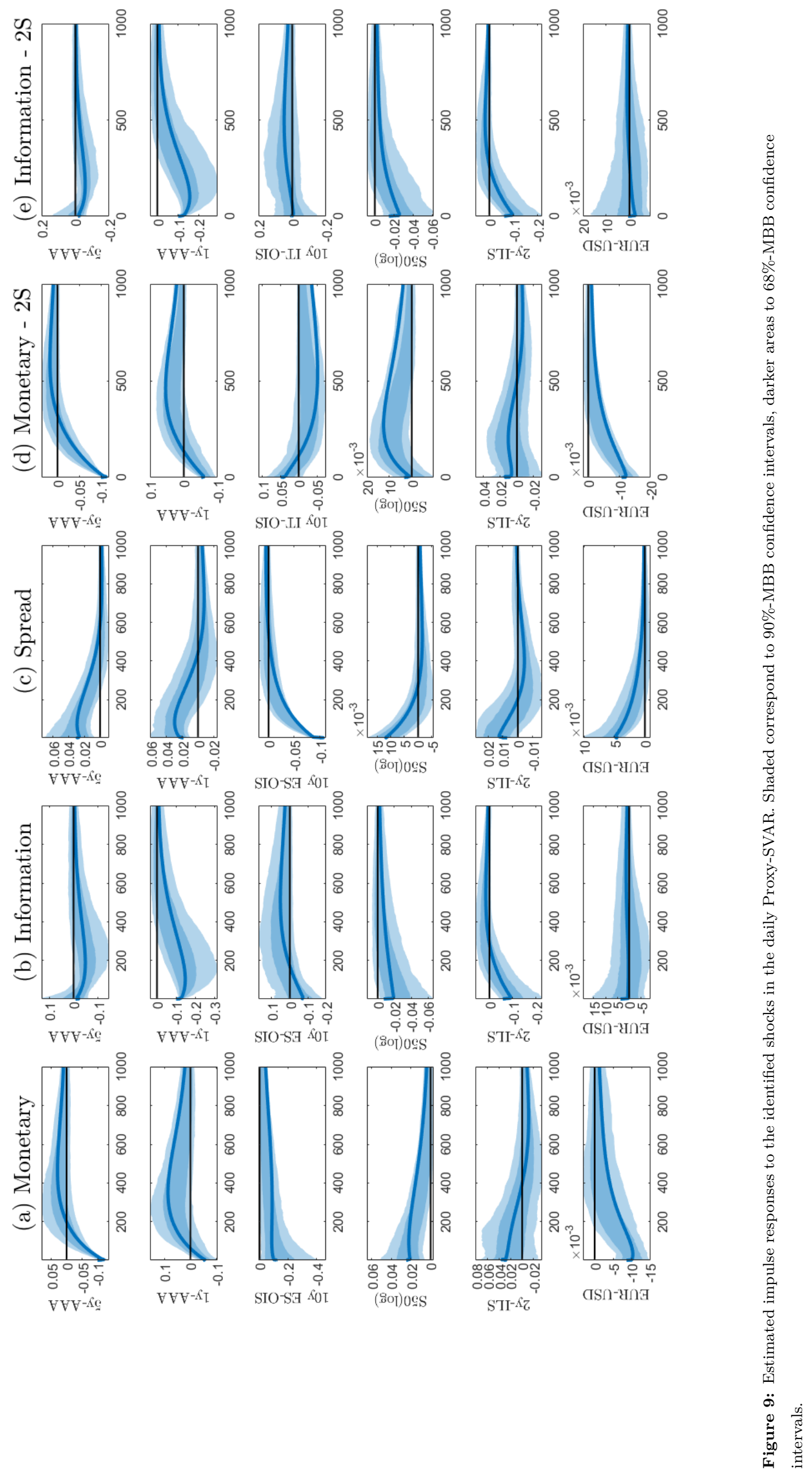

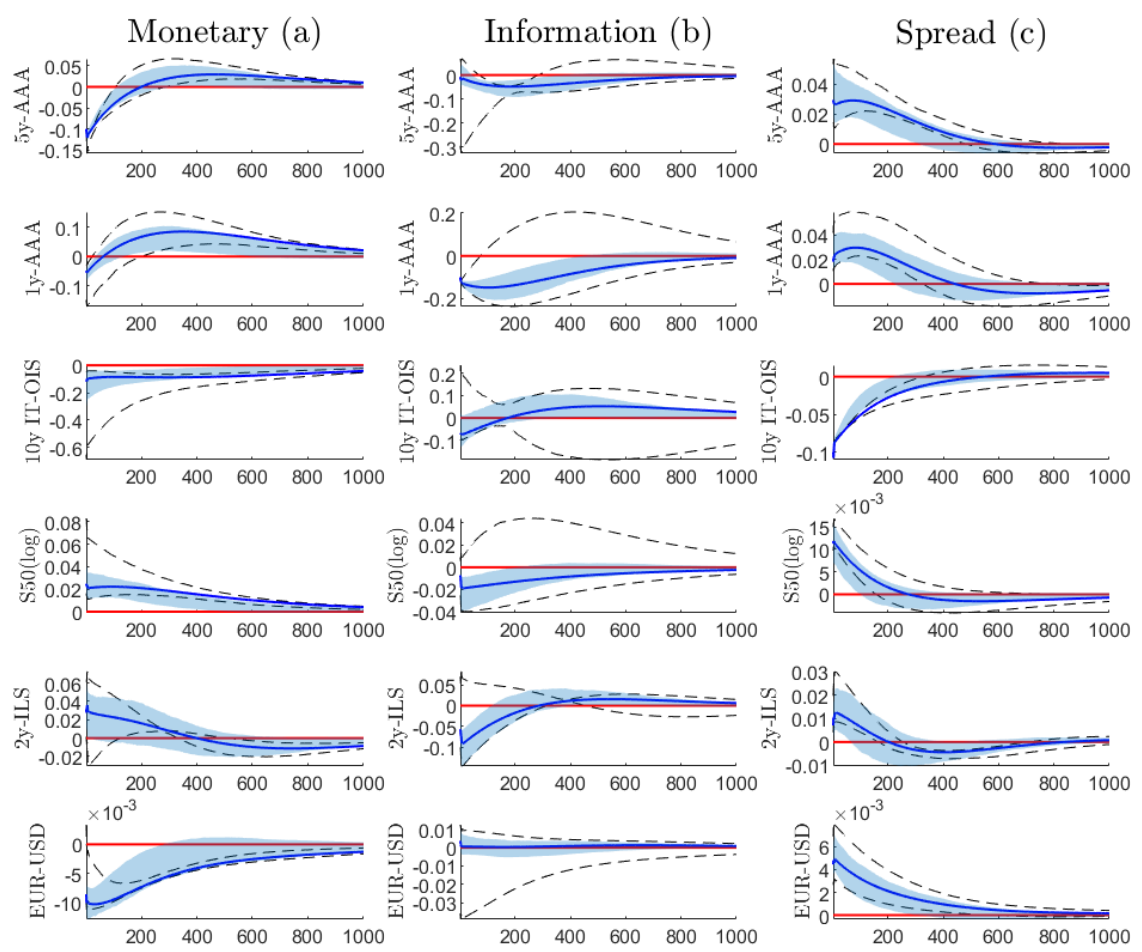

Figure 10: Blue lines correspond to the IRFs estimated by using the MT factors as external instruments, i.e. the responses plotted in Figure 9 Blue areas denote 68\%-MBB confidence bands. Dashed black lines denote the 16-84 quantiles of the distribution of IRFs obtained by estimating 1000 proxy-SVARs in correspondence of each possible choice of factors from the admissible set $\mathcal{F}_{t=1}^{T}$ (see Section 5 . 


\section{Monetary shock}
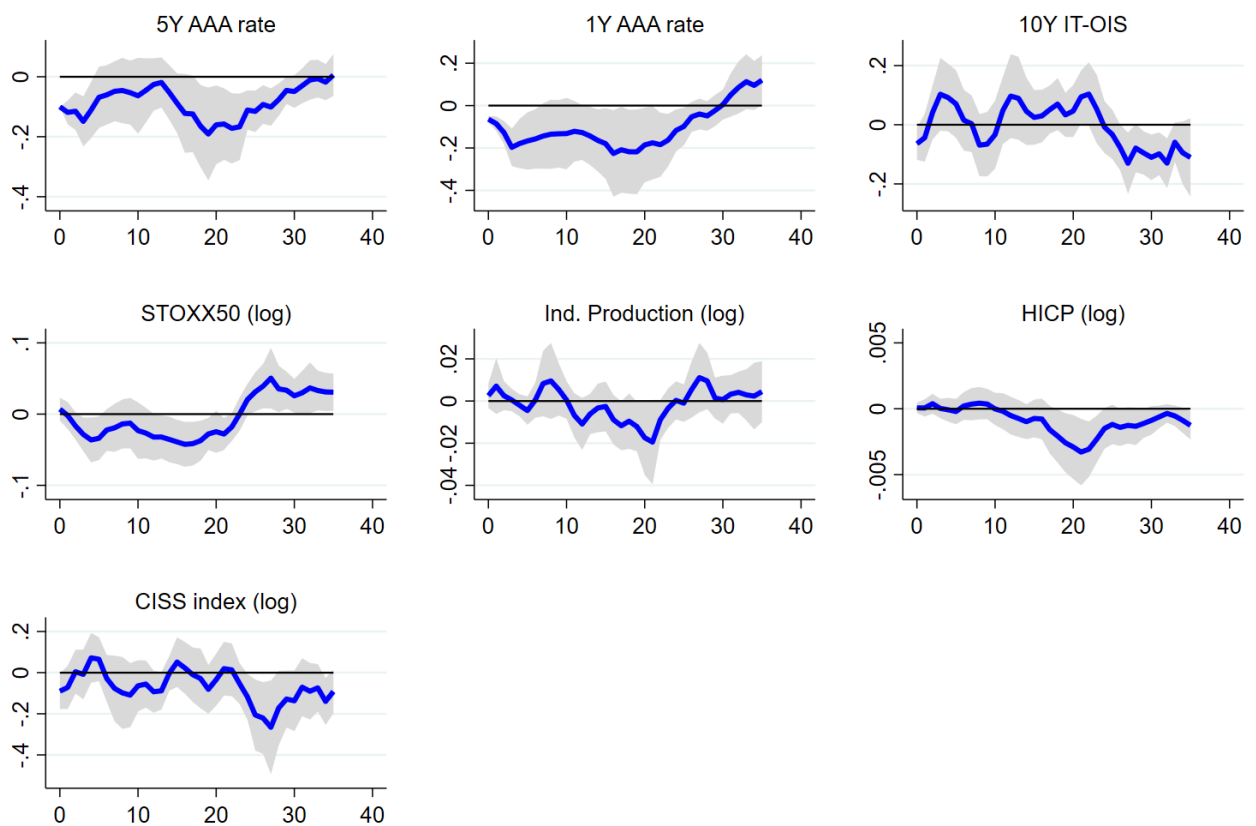

Figure 11: Responses to the monetary policy shock obtained from LP-IV regressions, monthly data. Shaded areas correspond to $90 \%$-confidence intervals (Newey-West-HAC).

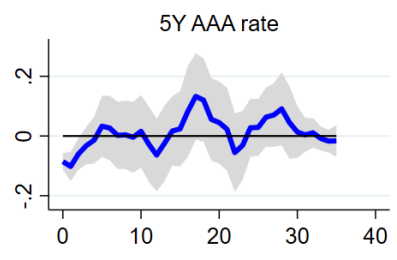

Information shock
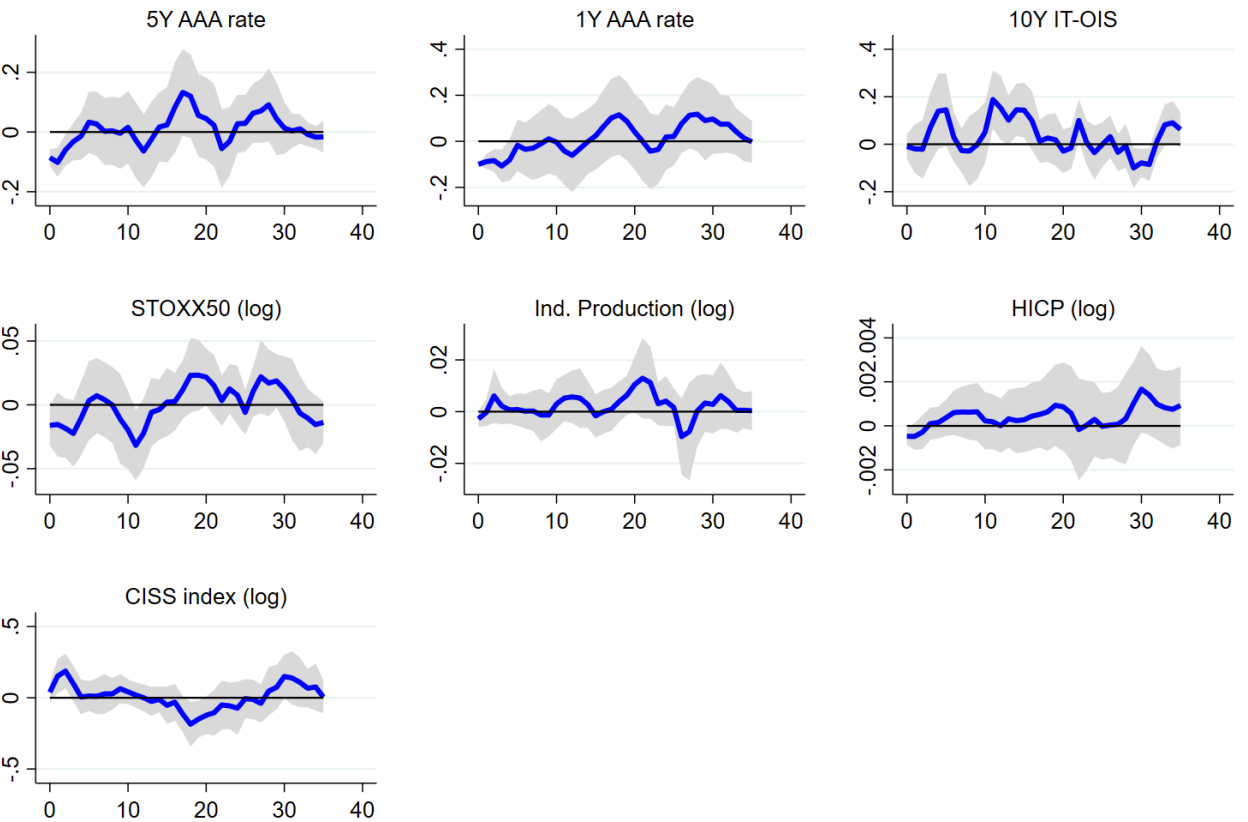

Figure 12: Responses to the information shock obtained from LP-IV regressions, monthly data. Shaded areas correspond to $90 \%$-confidence intervals (Newey-West-HAC). 


\section{Spread shock}
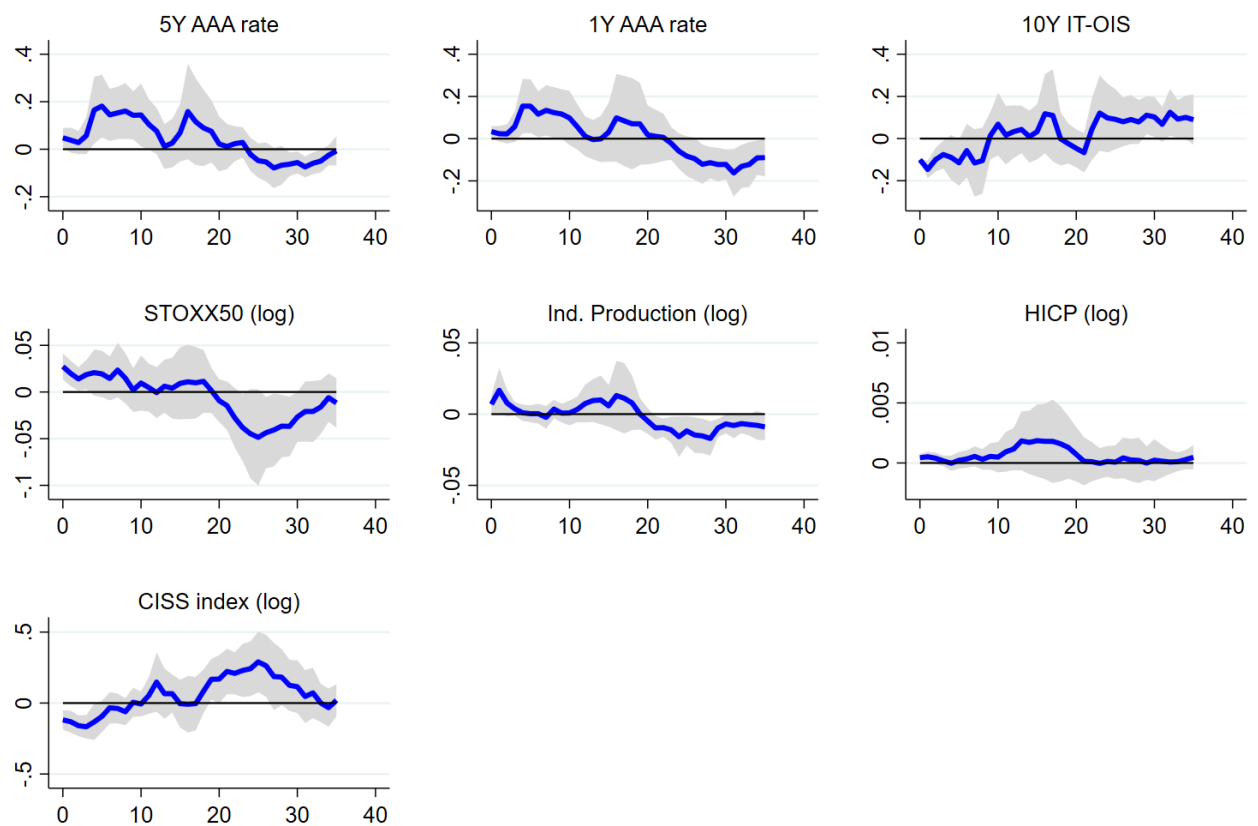

Figure 13: Responses to the spread shock obtained from LP-IV regressions, monthly data. Shaded areas correspond to $90 \%$-confidence intervals (Newey-West-HAC). 


\section{References}

Alessandri, P., Gazzani, A., and Vicondoa, A. (2021). The real effects of financial uncertainty shocks : A daily identification approach. Working Paper, Red Nacional de Investigadores en Economia.

Altavilla, C., Brugnolini, L., Gürkaynak, R. S., Motto, R., and Ragusa, G. (2019). Measuring euro area monetary policy. Journal of Monetary Economics, 108(2019):162-179.

Altavilla, C., Carboni, G., and Motto, R. (2015). Asset purchase programmes and financial markets: lessons from the euro area. ECB Working Paper Series.

Altavilla, C., Giannone, D., and Lenza, M. (2016). The financial and macroeconomic effects of the OMT announcements. International Journal of Central Banking, 12(3):29-57.

Altavilla, C., Pagano, M., and Simonelli, S. (2017). Bank exposures and sovereign stress transmission. Review of Finance, pages 2103-20139.

Andrade, P. and Ferroni, F. (2021). Delphic and odyssean monetary policy shocks: Evidence from the euro area. Journal of Monetary Economics, 117:816-832.

Angelini, G. and Fanelli, L. (2019). Exogenous uncertainty and the identification of Structural Vector Autoregressions with external instruments. Journal of Applied Econometrics.

Antolín-Díaz, J. and Rubio-Ramírez, J. F. (2018). Narrative sign restrictions for SVARs. American Economic Review, 108(10):2802-2829.

Bernanke, B. S. and Kuttner, K. N. (2005). What Explains the Stock Market's Reaction to Federal Reserve Policy? Journal of Finance, LX(3).

Caggiano, G., Castelnuovo, E., Delrio, S., and Kima, R. (2021). Financial Uncertainty and Real Activity: the Good, the Bad and the Ugly. European Economic Review, 136.

Campbell, J. R., Evans, C. L., Fisher, J. D. M., Justiniano, A., Calomiris, C. W., and Woodford, M. (2012). Macroeconomic Effects of Federal Reserve Forward Guidance. Brookings Papers on Economic Activity, (Spring):1-80.

Christiano, L. J., Eichenbaum, M., and Evans, C. L. (1999). Monetary policy shocks: What have we learned and to what end? Handbook of Macroeconomics, 1:65-148.

Cieslak, A. and Schrimpf, A. (2019). Non-monetary news in central bank communication. Journal of International Economics, 118:293-315.

Cochrane, J. H. and Piazzesi, M. (2002). The Fed and Interest Rates - A High-frequency Identification. American Economic Review, 92(2):90-95. 
Crosignani, M., Faria-e Castro, M., and Fonseca, L. (2019). The (Unintended?) consequences of the largest liquidity injection ever. Journal of Monetary Economics.

Darracq Pariès, M., Jacquinot, P., and Papadopoulou, N. (2016). Parsing financial fragmentation in the euro area: a multi-country DSGE perspective. ECB Working Paper Series, (1891).

Darracq Pariès, M., Müller, G., and Papadopoulou, N. (2020). Fiscal multipliers with financial fragmentation risk and interactions with monetary policy. ECB Working Paper Series, (2418).

De Grauwe, P. (2011). The Governance of a Fragile Eurozone. CEPS Working Paper.

De Grauwe, P. and Ji, Y. (2013). Self-fulfilling crises in the Eurozone: An empirical test. Journal of International Money and Finance, 34:15-36.

Dewachter, H., Iania, L., and Wijnandts, J.-C. (2016). The response of euro area sovereign spreads to the ECB unconventional monetary policies. National Bank of Belgium Working Paper Series, (309).

Foroni, C. and Marcellino, M. (2016). Mixed frequency structural vector auto-regressive models. Journal of the Royal Statistical Society., 179(2):403-425.

Foroni, C., Marcellino, M., and Stevanovic, D. (2019). Mixed-frequency models with movingaverage components. Journal of Applied Econometrics, (34):688-706.

Fry, R. and Pagan, A. (2011). Sign restrictions in structural vector autoregressions: A critical review. Journal of Economic Literature, 49(4):938-960.

Furlanetto, F., Ravazzolo, F., and Sarferaz, S. (2019). Identification of financial factors in economic fluctuations. Economic Journal, 129(617):311-337.

Gambetti, L. and Musso, A. (2017). The effects of the ECB's Expanded Asset Purchase Programme. ECB Working Paper Series.

Gertler, M. and Karadi, P. (2015). Monetary Policy Surprises, Credit Costs and Economic Activity. American Economic Journal: Macroeconomics, 7(1):44-76.

Gürkaynak, R. S., Sack, B., and Swanson, E. (2005). The sensitivity of long-term interest rates to economic news: Evidence and implications for macroeconomic models. American Economic Review, 95(1):425-436.

Hachula, M., Piffer, M., and Rieth, M. (2019). Unconventional Monetary Policy, Fiscal Side Effects and Euro Area (Im)balances. Journal of European Economic Association, 0(0):1-30.

Hamilton, J. D. (2008). Assessing Monetary Policy Effects Using Daily Federal Funds Futures Contracts. Federal Reserve Bank of St. Louis Review, 90(4):377-393. 
Hanson, S. G. and Stein, J. C. (2015). Monetary policy and long-term real rates. Journal of Financial Economics, 115(3):429-448.

Hoesch, L., Rossi, B., and Sekhposyan, T. (2019). Has the information channel of monetary policy disappeared? Revisiting the empirical evidence. Working Paper, Universitat Pompeu Fabra, (1701).

Jarocinski, M. and Karadi, P. (2020). Deconstructing Monetary Policy Surprises - The Role of Information Shocks. American Economic Journal: Macroeconomics, 12(2):1-43.

Jentsch, C. and Lunsford, K. G. (2019a). Asymptotically Valid Bootstrap Inference for Proxy SVARs. Federal Reserve Bank of Cleveland Working Paper.

Jentsch, C. and Lunsford, K. G. (2019b). The Dynamic Effects of Personal and Corporate Income Tax Changes in the United States: Comment. American Economic Review, 109(7):2679-2691.

Krishnamurthy, A., Nagel, S., and Vissing-Jorgensen, A. (2018). ECB Policies Involving Government Bond Purchases: Impact and Channels. Review of Finance, 22(1):1-44.

Kuttner, K. N. (2001). Monetary policy surprises and interest rates: Evidence from the Fed funds futures market. Journal of Monetary Economics, 47(3):523-544.

Lakdawala, A. (2019). Decomposing the Effects of Monetary Policy Using an External Instruments SVAR. Journal of Applied Econometrics, pages 1-17.

Lane, P. R. (2021). The compass of monetary policy: favourable financing conditions. Speech at Comissão do Mercado de Valores Mobiliários.

Leombroni, M., Vedolin, A., Venter, G., and Whelan, P. (2021). Central bank communication and the yield curve. Journal of Financial Economics, 141(3):860-880.

Ludvigson, S. C., Ng, S., and Ma, S. (2020). Uncertainty and Business Cycles : Exogenous Impulse or Endogenous Response? American Economic Journal: Macroeconomics.

Mertens, K. and Montiel Olea, J. L. (2018). Marginal tax rates and income: new time series evidence. Quarterly Journal of Economics, pages 1803-1884.

Mertens, K. and Ravn, M. O. (2013). The Dynamic Effects of Personal and Corporate Income Tax Changes in the United States. American Economic Review, 103(4):1212-1247.

Miranda-Agrippino, S. and Ricco, G. (2021). The Transmission of Monetary Policy Shocks. American Economic Journal: Macroeconomics.

Nakamura, E. and Steinsson, J. (2018). High-frequency identification of monetary non-neutrality: The information effect. Quarterly Journal of Economics, 133(3):1283-1330. 
Plagborg-møller, M. and Wolf, C. K. (2021). Local Projections and VARs Estimate the Same Impulse Responses. Econometrica, 89(2):955-980.

Sims, E., Wu, J. C., and Zhang, J. (2020). The Four Equation New Keynesian Model.

Snedecor, G. W. and Cochran, W. G. (1989). Statistical Methods. Iowa State University Press.

Stock, J. H. and Watson, M. W. (2018). Identification and Estimation of Dynamic Causal Effects in Macroeconomics Using External Instruments. Economic Journal, 128(610):917-948.

Swanson, E. T. (2017). Measuring the effects of Federal Reserve Forward Guidance and Asset Purchases on Financial Markets. NBER Working Paper Series.

Uhlig, H. (2005). What are the effects of monetary policy on output? Results from an agnostic identification procedure. Journal of Monetary Economics, 52(2):381-419.

Wright, J. H. (2019). Comment on "Measuring euro area monetary policy" by Carlo Altavilla, Luca Brugnolini, Refet Gürkaynak, Giuseppe Ragusa and Roberto Motto. Journal of Monetary Economics, 108:180-184. 


\section{A The spread shock: a stylized model and further evidence}

\section{A.1 A stylized model}

In this Appendix we rationalize the mechanism through which a central bank can affect real economic activity via a spread shock. To do so, we present a slightly modified, stylized version of the multiple equilibria model considered in De Grauwe and Ji (2013).

In the model, a sovereign country in a monetary union faces a choice of whether defaulting or not on its outstanding debt. Defaulting on sovereign debt provides some benefit to the government, as it is not forced anymore to collect taxes to fund interest expenses and repayment of existing debt. We assume that this benefit, $B$, is a negative function of the real economic activity level, $y$. When $y$ is low, tax revenues are low and public budget deteriorates. This increases the outstanding debt and make it even harder to collect more taxes to pay for interest expenses, thus the benefit of default increases. The cost of default is instead fixed and equal to $C$. We further assume that when the benefit of default exceeds the cost, the government defaults with probability $p$ which is an increasing function of the net benefit from default. Formally:

$$
p(B-C)=\left\{\begin{array}{l}
p \in(0 ; 1] \text { if } B-C>0 \\
0 \text { if } B-C \leq 0 .
\end{array}\right.
$$

with $\frac{\partial p}{\partial(B-C)}>0$ and $\lim _{(B-C) \rightarrow \infty} p=1$.

We distinguish between two scenarios, which will lead to two possible equilibria. In the first scenario, denoted scenario $\mathrm{E}$, default is expected by the investors with probability $p$ given in 16 . This probability is priced in sovereign bonds, which will carry a positive risk premium that goes to infinity as the net benefit of default, and thus $p$, increases. Assuming that investors are riskneutral, a no-arbitrage condition implies that the risk premium is given by $x=\frac{p}{1-p}(1+r)$, which is a convex and increasing function of $p$. The scenario E corresponds to the red lines plotted in the two graphs in Figure 14 In the bottom graph, the benefit $B$, denoted $B_{E}$ under scenario E, is plotted as a function of $y$. As $y$ decreases, benefit of default increases. The top graph shows possible equilibria in the real economic activity vs interest rates space, i.e. in a simplified textbook IS-LM fashion. The interest rate $i$ is made up by a risk-free component, $r$, and the risk premium component, $x$. Equilibrium is defined by a negatively sloped $I S$ curve and a positively sloped $L M$ curve, the latter summarizing the central bank's reaction function. In the scenario E, the relevant $L M$ curve is $L M_{E}$, which embeds the risk premium induced by investors' expectations.

In the second scenario, denoted scenario U, sovereign default is always unexpected. This translates in a different benefit function $B_{U}$ which, as detailed in De Grauwe and Ji (2013), is always smaller than $B_{E}$. This is motivated by the fact that when default is expected with some positive probability, risk premium increases thus making the cost of servicing the debt higher. This creates an additional incentive to default with respect to the unexpected default scenario in which the risk premium is always zero. In the scenario $\mathrm{U}$, the relevant $L M$ curve is $L M_{U}$, with the risk 
premium $x$ being equal to zero for levels of economic activity such that the $B_{U}$ curve stands below the line $C$.

Assume we start from the equilibrium in $\left(y_{1} ; i_{1}\right)$. Here $B_{U}<B_{E}<C$, so default does not occur. The risk premium is zero, hence $x_{1}=0$ and $i_{1}=r_{1}$. Assume now that a contractionary demand shock shifts the $I S$ curve on the left, obtaining the curve $I S^{\prime}$ in the graph. In the expected default scenario $\mathrm{E}$, the equilibrium will move to the point $\left(y_{2} ; i_{2}\right)$. Here we have $B_{E}>C>B_{U}$, i.e. the benefits of default will exceed the costs. According to [16, a positive probability of default, say $p_{2}>0$, occurs, and this translates into a positive risk premium $x_{2}\left(x_{2}=\frac{p_{2}}{1-p_{2}}\left(1+r_{2}\right)\right)$ which in turn determines the equilibrium level of the interest rate, $i_{2}=r_{2}+x_{2}$. Imagine that the central bank is able to shift expectations about the probability of default from scenario $\mathrm{E}$ to scenario $\mathrm{U}$. More precisely, for all output levels for which it holds $B_{E}>C$, the central bank acts to shift the benefit curve from $B_{E}$ to $B_{U}$. The risk premium therefore shifts to zero $\left(x_{3}=0\right)$ and since the relevant $L M$ curve is $L M_{U}$, the economy reaches the new equilibrium level $y_{3}$ where $B_{U}<C$. It turns out that default does not occur because of 16 . At the new equilibrium, the interest rate is equal to $i_{3}=r_{3}$ (recall that $x_{3}=0$ ).

Notice that multiple equilibria can occur in this stylized model only in the region of the graph in which the $B_{U}$ curve lies below the line $C$ and the $B_{E}$ lies above the line $C$. Indeed, only in this region the unexpected default scenario $U$ leads to a second equilibrium where zero probability of default occurs. Conversely, for $B_{U}>C$ (the left part of the graph), zero probability of default cannot be an equilibrium. In other words, in the far-left part of the graph, the central bank loses all its power to affect expectations and the risk premium.

The intervention of the central bank which shifts expectations about sovereign default reflects the idea behind the management of the spread shock we identify empirically in the paper. In this stylized model, in the face of a contractionary demand shock which triggers the probability of default of a peripheral country, the effects produced by the central bank intervention are: (i) Output increases from $y_{2}$ to $y_{3}$; (ii) the risk premium decreases from $x_{2}>0$ to $x_{3}=0$; (iii) the risk-free interest rate increases from $r_{2}$ to $r_{3}$.

In Section 5 we employ sign-restrictions to identify the spread factor from HF variations of asset prices to use as an instrument for the spread shock. More precisely, in (4) we have assumed that the spread factor reduces the risk premium on Italian bonds increases stock prices and increase OIS risk-free rates. These conditions are better understood if we focus on the effects produced by the central bank intervention in this stylized model. The shift from one equilibrium to the other amounts to a spread shock which decreases the risk premium from $x_{2}$ to $x_{3}$. The induced increase in output allows us to assume a positive reaction of stock prices, maintaining that stock prices correctly reflect expectations about real economic activity ${ }^{22}$ The increase of the risk-free

\footnotetext{
${ }^{22}$ More precisely, the effects on stock prices of moving from one equilibrium to the other could be mixed in theory, as the increase in prices due to the increase in $y$ can be counter-balanced by the increase in the discount rate $r$. We refer to Cieslak and Schrimpf (2019) for a comprehensive discussion on how non-monetary shocks can affect stock
} 
rate from $r_{2}$ to $r_{3}$ is embedded in our empirical sign-restrictions exercise: OIS rates increase in reaction to an expansionary spread shock. Clearly, assuming that we start from the equilibrium $\left(y_{3} ; i_{3}\right)$, a central bank can implement a contractionary spread shock if it shifts the economy back to the scenario E. All the effects examined above are reversed.

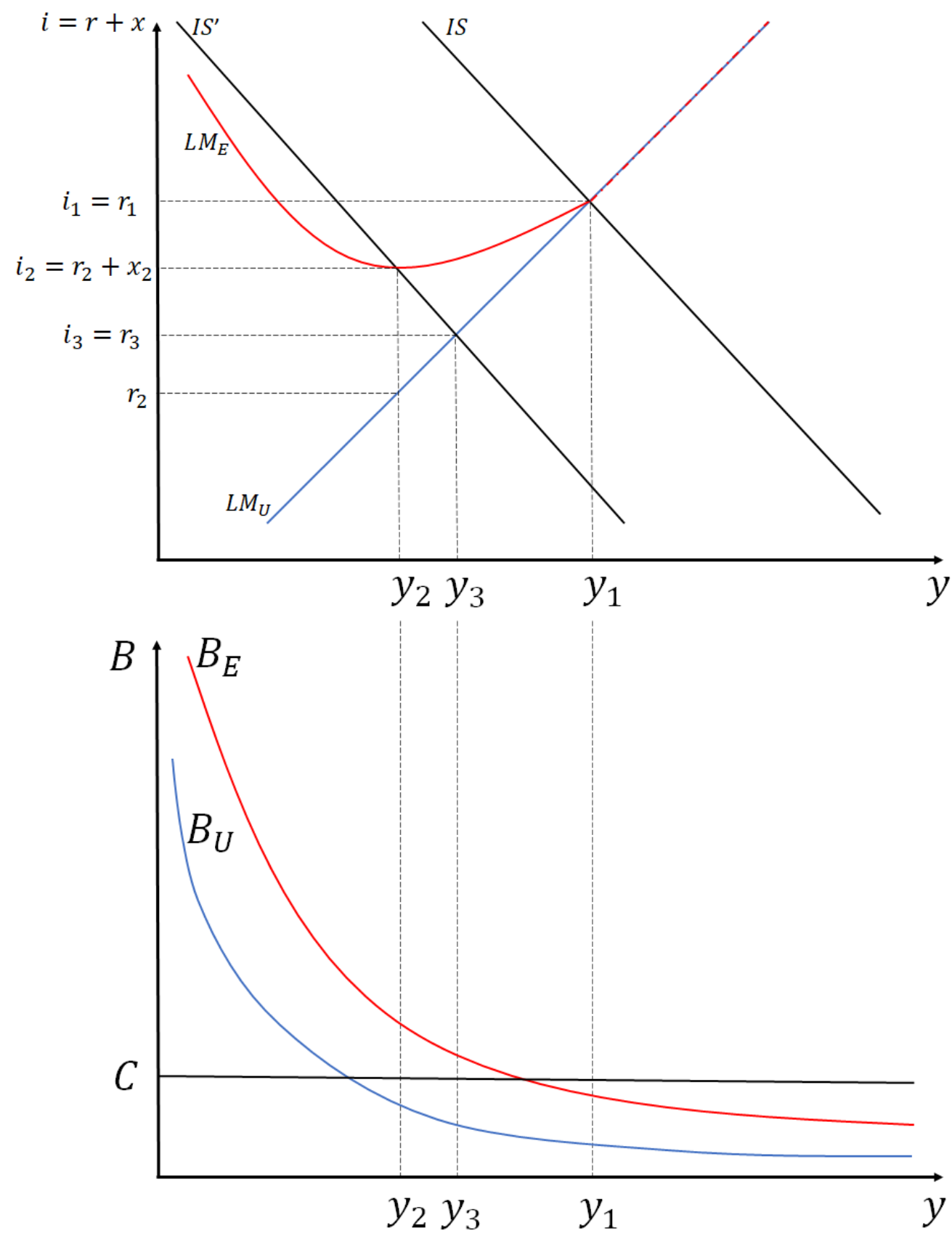

Figure 14: A stylized model of multiple equilibria.

prices. As they point out, the positive effect induced by the increase in $y$ should prevail. 


\section{A.2 Further reduced form evidence}

The events of the last decade have shown clearly that the ECB has used communication to exhibit a strong commitment to preserve the monetary union from an excessive fragmentation in the sovereign debt market. This policy has been as effective as the implementation of practical measures, eventually. The novelty of our approach resides in the acknowledgment that a spread shock, which lowers expectations about default(s) and thus sovereign risk premia, should be accompanied by an increase in the risk-free rates. This explains some of the puzzling comovements outlined in Section 3. A close inspection of some relevant ECB press conferences helps to confirm our 'spread shock' hypothesis.

On the September 6, 2012, the details of the Outright Monetary Transactions (OMT) were announced. The OMT is largely recognized as being one of the most effective measures in shifting sovereign default expectations downwards even though the funding line under the program has been never activated. During the ECB press conference held on September 6, 2012, we observe a large reduction in the risk premium on Italian bonds associated with an increase in long term OIS risk free rate; this is seen in the first row of Table 2.

The actual OMT announcement took place on August 2, 2012. This date is actually a quite peculiar case because the OMT announcement has been initially interpreted as a decision that the ECB was not willing to fully protect countries in trouble. This is why one can observe a steep increase in the risk premium. This initial reaction was then counterbalanced in the subsequent days. What is interesting for us, though, is that this 'restrictive' spread shock, is linked to a decrease in the OIS rate, as expected (see Table 2). 'Il Sole 24 ore', the main Italian financial newspaper, commented market reactions on August 3, 2012, by writing (our translation): 'In the current situation, with high spreads and highly fragmented markets, the effects of monetary policy do not transmit to the whole Eurozone.' In other words, the easing monetary policy, measured by the reduction in OIS rates, did not spill over to the Italian risk premium. The interpretation we give in this paper goes the other way round: the restrictive spread shock, measured by the increase in the Italian risk premium, spilled over to OIS rates, reducing them.

Another clarifying example is July 26, 2012, the day the famous 'whatever it takes' speech was held by Mario Draghi. In that day we observe a large decrease in the periphery spreads while the 10-year OIS rate increased, as expected, in response to a spread driven monetary policy shock.

By exploiting the predicted negative comovement of OIS rates and sovereign spreads in response to a spread shock, we are able to disentangle it from the unconventional monetary shock. An example of this latter type of mechanism is observed on January 22, 2015 when the APP was announced: we observe a similar reaction of the 10-year OIS rate and the 10-year IT-OIS spread (see Table 2). This fact appears consistent with the idea that an expansionary unconventional monetary policy like the QE reduces risk premia.

Summing up, we expect to observe a positive comovement of long term OIS rate and the pe- 
ripheral risk premium when a monetary shock is occurring and a negative comovement when the spread shock is instead at work.

\begin{tabular}{c|cc}
\hline Episode & 10-year OIS surprise & 10-year spread IT-OIS surprise \\
\hline $6^{\text {th }}$ September 2012: OMT announcement & 0.12 & -8.87 \\
$2^{\text {nd }}$ August 2012: OMT announcement & -6.09 & 38 \\
$22^{\text {th }}$ January 2015: QE announcement & -8.74 & -14 \\
\hline
\end{tabular}

Table 2: Surprises around ECB press conferences in the 10-year OIS rate and in the 10-year spread ITA-OIS on three relevant dates. Variations in basis points.

\section{B Two-shocks financial proxy-SVAR}

In this Appendix we provide more details on the daily proxy-SVAR featuring two structural shocks alone whose estimated impulse response functions are plotted in columns (d) and (e) of Figure 9 and commented in Section 6 of the paper.

The general setup and estimation method is the same as the one discussed in Section 5 of the paper, the main differences being that now $k=2$ in so that $z_{t}$ and $\varepsilon_{r, t}$ are $2 \times 1$. In particular, $z_{t}$ and $\varepsilon_{r, t}$ collect the monetary policy factor/shock and the information factor/shock, respectively. The monetary and information factors included in $z_{t}$ are extracted from HF surprises using the set of restrictions displayed in equation (3) when using a two-factors structure. $r_{t}$ is a $2 \times 1$ vector which contains the 5-year and the 1-year sovereign AAA-rated yields, constructed by the ECB by averaging yields from euro area sovereign rates with triple A rating. These two variables constitute the policy indicators for the monetary and information shocks, respectively. $x_{t}$ contains the log of the STOXX50 index, the 2-year inflation-linked swap rate and the log of the Eur-Usd exchange rate. In this specification, the 10-year spread IT-OIS is included in the variables in $x_{t}$. It turns out that $y_{t}=\left(r_{t}^{\prime}, x_{t}^{\prime}\right)^{\prime}$ is always $6 \times 1$. The $2 \times 2$ matrix of relevance parameters $\phi$ is specified upper triangular.

\section{Robustness: Spanish sovereign spreads}

In sections 5,6 and 7 we estimated the spread shock by focusing on the dynamics of the sovereign spread on Italian bonds. This choice is motivated by the fact that Italy is the largest of the peripheral countries of the euro area in terms of economic size, and its sovereign debt is by far the largest in the periphery. Furthermore, Italy features some characteristics which makes it 
particularly appealing for the analysis we have in mind: (i) pressures on its sovereign debt market has been varying over time but never went too far as for Greece, which reaches in practice a sovereign default and were not temporary as it has been the case for Ireland, whose debt crisis was confined to the aftermath of the Great Recession.

In this Appendix we repeat the analysis by focusing on the sovereign spread on sovereign bonds of Spain, the second largest country in the periphery, which followed closely Italian sovereign spread over the years. Results are approximately the same of those obtained when using Italian spreads, showing that the main results of this paper are not specific to the case of Italy ${ }^{23}$

We repeat the factor analysis performed in Section 5 and replace the HF variations of Italian sovereign spreads $\Delta\left(I T_{m, t}-O I S_{m, t}\right)$ with Spanish counterparts, $\Delta\left(E S_{m, t}-O I S_{m, t}\right)$. Equation (4) reads now as follows:

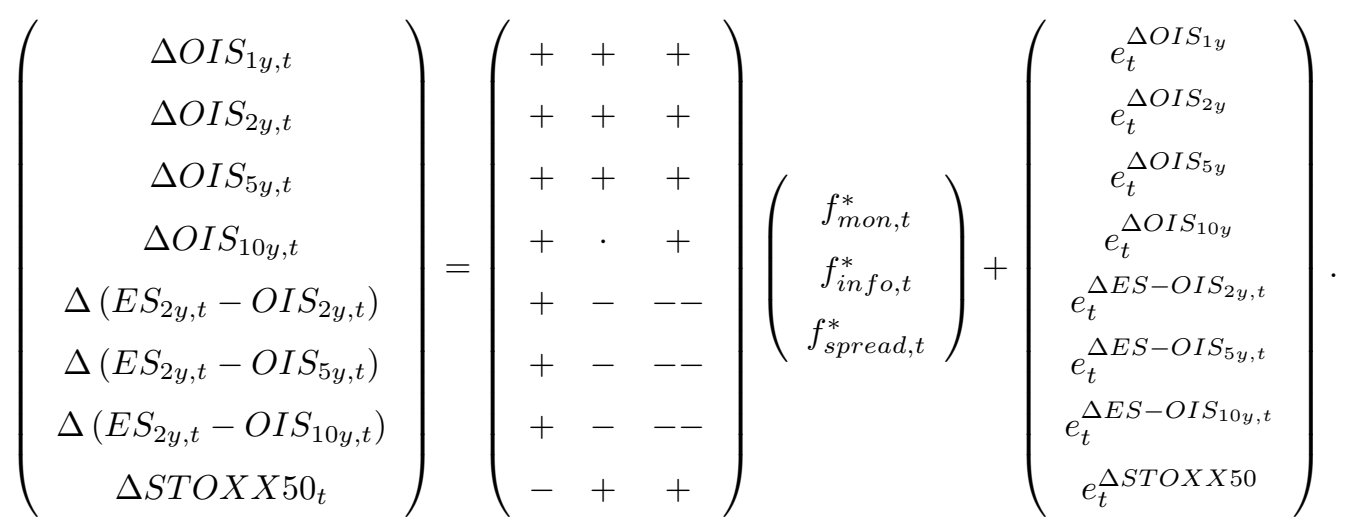

The remaining part of the methodology we employed remains unchanged. Table (3) displays the cross-correlations among the three Median Target (MT) factors extracted when using Spanish sovereign spreads and the baseline MT factors extracted using Italian sovereign spreads. We detect a strong correlation between the pairs of factors of the same nature from the two specification. For instance the MT information factor from the baseline specification (Italian sovereign spreads) it $99 \%$ correlated with the MT information factor from the "Spanish model". This confirms the hypothesis that HF variations, around ECB press conferences, in the sovereign spreads of Italy and Spain are actually measuring movements of the same risk premium.

We then repeat the analysis made in Section 6 and use the estimated MT factors - Spain as external instruments in a proxy-SVAR at daily frequency. All the choices made in Section 6 remain unchanged but we also replace, among the set of endogenous variables, the 10-year spread IT-OIS with the Spanish counterpart: the 10-year spread ES-OIS. Figure 15 show the estimated impulse response functions with MBB confidence bands (blue lines and blue areas) and compare them with the impulse responses obtained in Section 6, when using Italian sovereign spreads. Figure 15 shows clearly how the estimated dynamic effects produced by the three shocks are practically the same

\footnotetext{
${ }^{23}$ We do not extend the analysis also to Portugal, as the EA-MPD database we employ for HF variations does not contain $\mathrm{HF}$ variations of Portuguese sovereign rates.
} 


\begin{tabular}{l|ccc}
\hline & MT monetary factor - IT & MT spread factor - IT & MT information factor - IT \\
\hline MT monetary factor - ES & 0.96 & 0.01 & 0.01 \\
MT spread factor - ES & -0.10 & 0.95 & 0.01 \\
MT information factor - ES & -0.04 & -0.05 & 0.99 \\
\hline
\end{tabular}

Table 3: Correlations among the estimated MT factors obtained from Italy and Spain

when using Spanish instead of Italian sovereign spreads. The results obtained in this paper are therefore valid for Spain as well. 

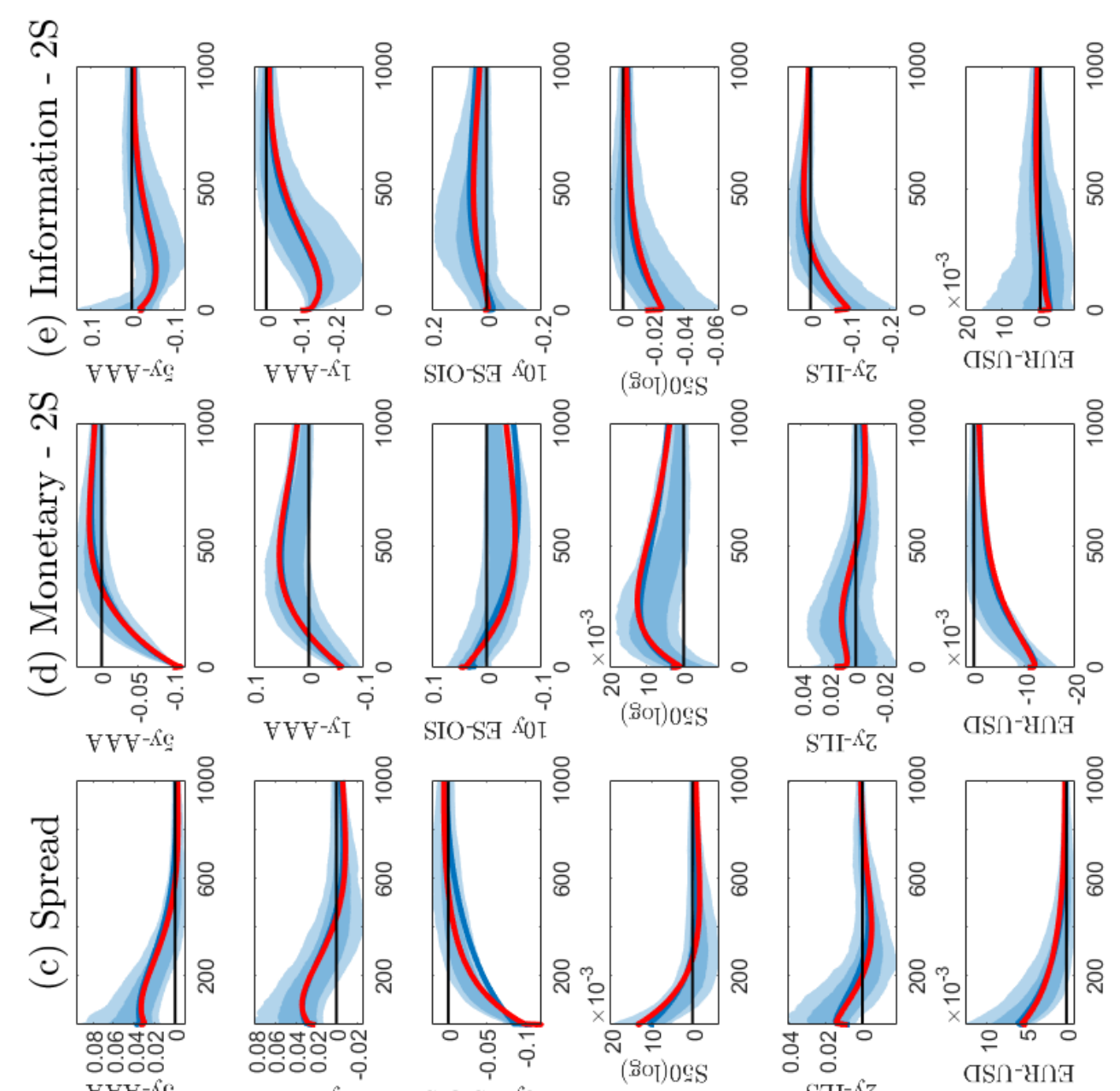

สSก-่กส
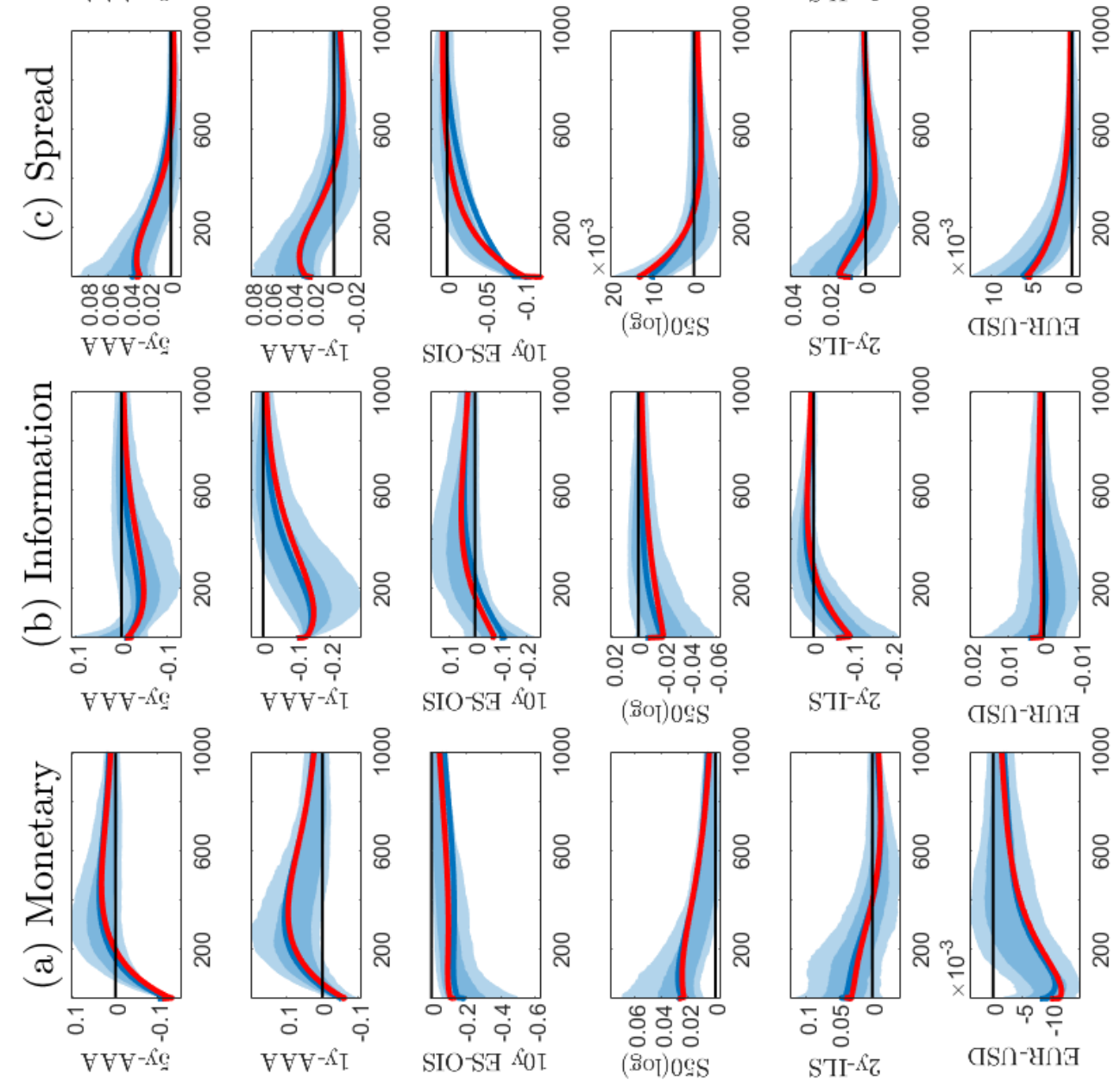

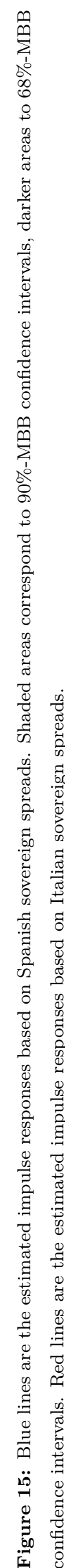




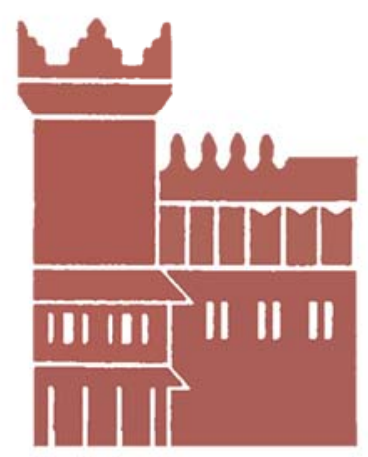

Alma Mater Studiorum - Università di Bologna DEPARTMENT OF ECONOMICS

Strada Maggiore 45

40125 Bologna - Italy

Tel. +39051 2092604

Fax +390512092664

http://www.dse.unibo.it 